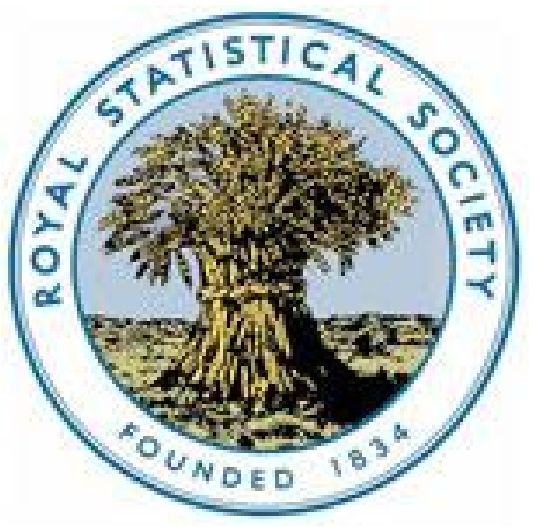

\title{
WILEY
}

\section{Two Hundred and Fifty Years of Small Pox in London}

Author(s): William A. Guy

Source: Journal of the Statistical Society of London, Vol. 45, No. 3 (Sep., 1882), pp. 399-443

Published by: Wiley for the Royal Statistical Society

Stable URL: http://www.jstor.org/stable/2979319

Accessed: 26-06-2016 20:46 UTC

Your use of the JSTOR archive indicates your acceptance of the Terms \& Conditions of Use, available at

http://about.jstor.org/terms

JSTOR is a not-for-profit service that helps scholars, researchers, and students discover, use, and build upon a wide range of content in a trusted digital archive. We use information technology and tools to increase productivity and facilitate new forms of scholarship. For more information about JSTOR, please contact support@jstor.org.

Royal Statistical Society, Wiley are collaborating with JSTOR to digitize, preserve and extend access to Journal of the Statistical Society of London 
Two Hundred and Fiftr Years of Small Pox in London. By William A. Gux, M.B., Cantab., F.R.C.P., F.R.S., one of the Honorary Vice-Presidents of the Statistical Society.

[Read before the Statistical Society, 20th June, 1882.]

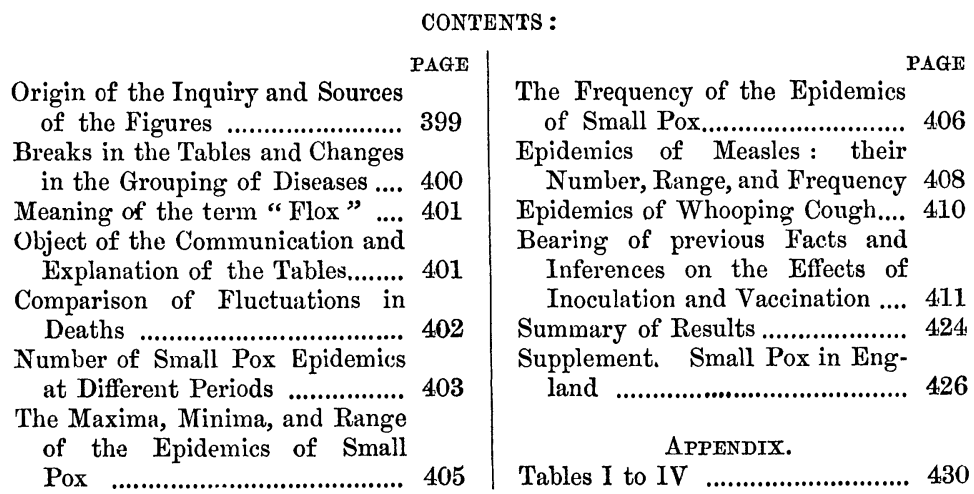

The limited time ultimately allotted to me for the preparation of this paper has caused me to restrict myself to the figures relating to small pox in London, reserving for possible future use the figures for England, which accordingly I hold in reserve. The years comprised in this survey may be roundly stated at two centuries and a half-two hundred and fifty years-or, more exactly, at the interval between 1629 and 1881, both inclusive, but with breaks presently to be pointed out and described.

It is well, perhaps, that I should show how it came to pass that I entered upon this inquiry. I did not undertake it in the spirit of controversy, but because I wished to find continuous occupation in copying and calculating for one who was eminently qualified to render me assistance in these matters, and who happened at that time to be disengaged. Hence it has come to pass that both the original figures, and the calculations based upon them, have been verified, and all sources of error in the figures on which this communication is based thus excluded, except such as are incidental to printed records copied from the manuscripts of those who furnished the returns. I must add that, when I took these figures in hand, I did not know to what conclusions they would lead me, though I VOL. XLV. PART III. 
felt convinced that, whatever they proved to be, they must have some bearing (perhaps an important one) on the question of the effect, favourable or unfavourable, of inoculation, and the efficacy of vaccination as a preventive of small pox.

The sources from which my original figures, embodied in Table I of the Appendix, were derived, are:-

1. "A Collection of the Yearly Bills of Mortality, from 1657 to " 1758 inclusive. Together with several other Bills of an earlier " date." [These tables are followed by four essays, of great interest to the statist and actuary, by Captain Graunt, Sir William Petty, Corbyn Morris, and J. P., Esq., all Fellows of the Royal Society. It bears date 1759, and is published by A. Millar, in the Strand.]

2. "Mortality of the Metropolis. A Statistical View of the "Number of Persons reported to have Died of eaeh of more than " 100 kinds of disease and casualties within the bills of mortality " in each of the two hundred and four years, 1629-1831," \&c. "By "J. Marshall, Esq. 1832." Table I of the Appendix is compiled from the figures given in this work.

3. "The Registrar-General's Annual Summary of Births, Deaths, " and Causes of Death, in London and other cities. 1881." [Published 1882.]

4. "Observations on the Increase and Decrease of Different "Diseases, and particularly of the Plague. By William Heberden, “jun., M.D., F.R.S. 1801."

I am indebted, as I have just stated, for the figures relating to the years from 1629 to 1831 inclusive to the tables of J. Marshall ; and for those from 1841 to 1881 inclusive to the "Annual Sum"mary" of the Registrar-General, Table XI, pp. xx and xxi.

In the series of returns thus extending from the year 1629 to the year 1881 inclusive, there are certain breaks or interruptions, which I must point out, and certain changes in the grouping of diseases which I must explain.

The breaks or interruptions occur as follows:-

a. After the year 1636, a break in the bills of ten years, with a resumption of them in 1647 .

$b$. After the year 1831, a break of nine years, with a resumption of the returns in their improved form by the registrar-general in 1838 , and in their more mature form in 1841.

The changes in the grouping of diseases are the following:-

a. Small pox included in the same group with flox, as "flox and " small pox," from the year 1629 to the year 1636 inclusive, and from the year 1647 to the year 1686 inclusive.*

* In Marshall's tables the heading "Small Pox" is adopted: the mixed heading "Flox and Small Pox," and "Flox, Small Pox, and Measles" in the anonymous compilation No. I. 
$b$. Flox, small pox, and measles comprised in one group from the year 1687 to 1701 inclusive; the cases of measles in the last year of the series being returned as four in number.

c. Small pox, as a distinct heading, and measles also distinct, from the year 1702 forwards; so that, by deducting the four cases of death by measles from the return of 1701, we obtain a continuous return of deaths by small pox from 1701 to 1831 inclusive, and again from 1841 to 1881 inclusive. Hence we can compare, if we will, the forty years 1841 to 1880 , with groups of forty years in the interval 1701 to 1831 , being one hundred and thirty years; and this in respect both of small pox and measles. If we would make the fourteen years from 1687 to 1700 inclusive, part of the whole return, we should have to deduct the deaths by measles as estimated, say, from an average of five years preceding and following these fourteen years.

Of the term "flox," associated with small pox in the earlier returns, I may state that I have taken great pains to ascertain its true meaning by consulting old medical dictionaries and other works in which it was likely to be emplcyed, and have arrived at the conclusion that, whatever its precise meaning may have been, it was certainly a form of small pox. I find, for instance, in that remarkable compilation, "A general chronological history of the " air, weather, seasons, meteors, \&c.," published in 1749 , the "flux "sort" mentioned as a form of the disease which is never, or rarely, followed by any other form. It is added that "having flux, "or, distinct kinds," does not prevent "the spurious sorts, as “ chicken pox, crystals, \&c."*

It will be understood, then, that the primary object of this commanication is to throw light on the great and important epidemic malady, small pox. To assist me in this inquiry I make use of the facts relating to another epidemic, measles, a disease of which the register extends over the same long period of time; and which like small pox, has outward appearances and leading symptoms easily recognised. So that in the earlier times, when the bills of mortality were compiled by the parish clerks from data supplied

* I must here acknowledge my obligations to my friend Dr. John Harley for the careful, but vain, search, he has made after the word "flox." The word "flux," as he states, is always used in reference to discharges, and he shows by the following case cited from the "Rational Physitian's Library" that "small pocks and " bloody flux" are found associated as in obs. 71 of that work. "A boy, 5 years " old, being stricken sick of the small pocks, the third day was taken with a " bloody flux, with a frequent desire of going to stool, he voided flegmatic and " snotty excrements with great store of blood. The pocks were small, white, and " flat." Dr. Harley expresses the opinion that the word "flox" used in connection with small pox, must refer to cases of this kind, which in olden times, if we are to judge by their comparative frequency now, must have been common. I could not find the word "flox" in the three volumes of the "Leechdoms." 
by women searchers, assisted by the medical practitioners of their day, the true cause of death was almost as likely to be reported as in these later days, when the facts are brought together by the registrar-general acting on the certificates of medical men.

These two orders of facts are displayed in Table $I$ of the Appendix in parallel columns with the deaths from all causes, in the same years, reported by the same agents; while two other parallel columns exhibit the ratios per thousand resulting from the comparison of the deaths from small pox and measles respectively with the deaths from all causes, accidents, and still-births included, as well as the two diseases small pox and measles themselves.

In the absence during the earlier periods of reliable data respecting population, and in the face of frequent changes in the area from which the death returns were drawn, as well as of sundry omissions of places and classes of people, I have been compelled to have recourse to the deaths from all causes as my standard of comparison. That these deaths are but rough approximations to the truth, especially in the days preceding the Registration Bill, I am well aware; but a glance at the figures themselves will convince us that the fluctuations in the deaths, both from special causes and from all causes collectively, are made plain, though wanting in exactness.*

Thus, if I take the figures which represent the deaths in London for the ten years ending 1680,1780 , and 1880 in the three centuries over which the figures extend-the seventeenth, eighteenth, and nineteenth centuries - and place them in order, each figure under that for the corresponding year, and if I further omit the last three figures of each year's return, I obtain the following series, which may be said to lend support the one to the other :-

Ten years ending $1680 \ldots \ldots . .16,18,17,21,18,19,19,21,22,21$. Range 22 to 16 .

" $\quad 1780 \ldots . . .22,26,22,21,21,19,23,20,20,21 . \quad$ " $26,19$.

» $1880 \ldots \ldots . .80,71,75,77,82,88,77,84,84,81$. " 88,71 ,

It will be seen that the figures in the third line, being those for the present century, and for the London of our own time, are about four times as numerous as those for the city of the seventeenth and eighteenth centuries, as comprised within the bills of mortality; so that if we divide the figures of this third line by four, we obtain a series nearly resembling in general character the series in the first and second lines.

* Heberden, after noting the "mistakes and misrepresentations" to which particular diseases are liable, states that even in the smaller divisions of the subject " the correspondence of one year, and of one week with another, is such as must

" convince every attentive observer that a considerable degree of credit is due to " these reports." 
Again, if I take the figures for small pox for the same years in the same three centuries and treat them in the same way, but omitting the last two figures, I obtain similar fluctuations, with a striking indication (which I notice in passing) of a falling off in the supply of deaths by small pox in the century in which we are living. The figures are as follows:-

Ten years ending $1680 \ldots \ldots . .7,11,8,25,10,4,17,18,20,7$. Range 25 to 4 . " $\quad 1780 \ldots . . .17,40,10,25,27,17,26,14,25,9 . \quad$ " $49,9$. " $\quad 1880 \ldots . . . .79,18,1, \cdot 57, \cdot 46,7,26,14,4,5 . \quad$ " $79,446$.

The first two lines of this comparison show similar fluctuations, though the scale is different, while the figures of the third line exhibit an amount of fluctuation that cannot fail to attract attention. It is clear that we are here dealing in this nineteenth century with an exceptional order of facts, brought about by some very potent force or forces. How exceptional it is we shall clearly perceive if we bear in mind what has just been stated, that the figures of the third line relate to the present century, when the deaths in London from all causes are four times as numerous as in the two previous centuries.

From these needful introductory explanations I pass on to consider the lessons which may be deduced from these returns. In the first place, it is obvious that we may learn something from them of the frequency of epidemic outbreaks of small pox at different periods; also something of the maxima and minima to which the deaths from small pox have risen and fallen; also something of the intervals between the epidemics. Having exhausted this field of inquiry, we may also hope to learn something from a like survey of the facts relating to measles, and still more from a careful comparison of the results of the one survey with those of the other. This may lead to new inquiries respecting certain other epidemics, which cannot be traced throughout the whole period of two hundred and fifty years, but may still extend over periods long enough to confirm or invalidate the conclusions to which a study of the retarns for small pox and measles had conducted us. I shall treat the questions here indicated under distinct headings in the order in which they occur.

\section{Number of Small Pox Epidemics at Different Periods.}

Though we all understand what an epidemic malady means, and know that it implies a considerable and irregular excess of attacks and deaths in certain years as compared with others, and though, as an example in point, we should speak of small pox as epidemic and pulmonary consumption as non-epidemic, we are not able to state with numerical precision what amount of fluctuation or difference 
from year to year shall be held to constitute an epidemic, or what multiple of the average or minimum of deaths. In the absence of any numerical rule applicable to this subject, we shall not go far wrong if, passing in review the figures relating to a term of years, we lay hold of those that stand out in relief (if I may so express myself) from the figures which precede and follow. In the case of small pox, I find such convenient figures in all numbers exceeding 100, and, with a view to a comparison of one period with another, I name 100 deaths or upwards an epidemic. But it may be well to state that I attach no importance to the word "epidemic," or the precise figure which it is made to represent.

Such being the meaning I attach to the term epidemic in this special case of small pox, I proceed to show the number of such epidemics at different periods of time, and, that I may avoid all appearance of selection, I display the epidemics as they have occurred in periods of thirty and forty years, and in the three centuries to which my tables relate.

\section{TABLe I.}

\begin{tabular}{|c|c|c|}
\hline $\begin{array}{c}\text { Arrangement by Periods of Thirty } \\
\text { Years. }\end{array}$ & & $\begin{array}{c}\text { Arrangement by Periods of For } \\
\text { Years. }\end{array}$ \\
\hline 1647-76 (Flox and small pox) .... & 6 & 1647-86 (Flox and small pox) \\
\hline $702-31$ & 6 & $1702-411 \ldots \ldots \ldots \ldots \ldots \ldots \ldots \ldots \ldots \ldots \ldots \ldots$ \\
\hline '32-61 (62-91 & 9 & ' $42-81$. \\
\hline (n) & I3 & $1801-31$ (thirty years) .. \\
\hline '41-70 & 0 & 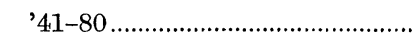 \\
\hline
\end{tabular}

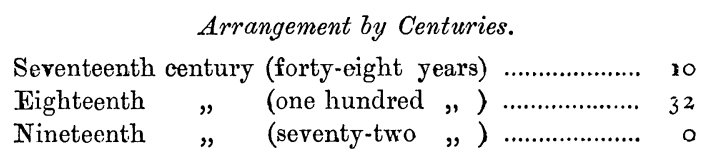

The three sections of this table agree in displaying the present century as free from epidemics of small pox, when the ratio of 100 to 1,000 of all causes, or 10 per cent., is taken as the measure and definition of an epidemic. They also agree in representing such epidemics as of most frequent occurrence in the latter half of the eighteenth century. For when the figures are grouped by centuries, it is seen that the forty-eight years of the serenteenth century, when doubled so as to approximate to the number of years in the eighteenth, yield about twenty epidemics to thirty-two in the eighteenth centary. The entire absence of epidemics in the nineteenth eentury, when 100 deaths per $\mathrm{r}, 000$, or ro per cent., are taken as the mark and measure of an epidemic, is the salient and notable fact which my inquiries up to this point have established.

Lest, however, this selection of a particular ratio should be deemed arbitrary, and possibly misleading, I construct a table in 
which I display side by side the numbers of years in which the ratios exceed the several figures 50,75 , 100, and 150 per 1,000 .

TABLE II.

\begin{tabular}{|c|c|c|c|}
\hline \multirow{2}{*}{ Ratios. } & \multicolumn{3}{|c|}{ Centuries. } \\
\hline & Seventeenth. & Eighteenth. & Nineteenth. \\
\hline 50 per $1,0 c 0$ and less than 75 & I I $(48 \mathrm{yrs})$ & 22 (100 yrs.) & 10 (72 yrs.) \\
\hline $100 \ldots \ldots$. & 4 & 27 & 4 \\
\hline $150 \ldots \ldots$. & 10 & 29 & $\circ$ \\
\hline 150 and upwards & & 4 & $\circ$ \\
\hline 50 and upwards & 25 & 82 & 14 \\
\hline
\end{tabular}

These, too, are very striking figures. The eighteenth century again shows a marked excess of epidemics. For while it equals the seventeenth century when the ratio of 50 and less than 75 is taken as the measure of an epidemic, it exceeds it more than fourfold when the epidemic standard is taken at 75 and less than 100. When the standard is fixed at 100 and less than 150 , the figure for the eighteenth century for the same number of years exceeds that for the seventeenth as 29 exceeds 20 , while for the higher standard of 150 and upwards it displays four instances, though in the seventeenth and nineteenth centuries no single year attains this highest standard. If we add all the figures of the three columns together, the sum of 82 is more than three times the sum (25) for the seventeenth century, and (the seventy-two years of the nineteenth century being augmented by a third) the ratio for the nineteenth century proves to be less than a fourth of that for the eighteenth, and considerably less than that for the seventeenth.

\section{Of the Maxima and Minima, and Range of the Epidemics.}

If now we again assume 100 deaths by small pox in 1,000 deaths from all causes as the measure of an epidemic, it is natural to inquire what are the highest and what the lowest figures attained in the several centuries. This is shown in the next table.

TABLE III.

\begin{tabular}{|c|c|c|c|c|}
\hline \multicolumn{2}{|r|}{ Centuries. } & \multirow{2}{*}{$\begin{array}{l}\text { Maxima. } \\
124^{\circ} 40\end{array}$} & \multirow{2}{*}{$\frac{\text { Minima. }}{2 \cdot 98}$} & \multirow{2}{*}{$\frac{\text { Range. }}{12 I^{\circ} 4^{2}}$} \\
\hline Seventeenth & entury (48 years) ........ & & & \\
\hline Eighteenth & $" \quad(100 \quad)$, & $183^{\circ} 94$ & $15 \cdot 32$ & $168 \cdot 62$ \\
\hline Nineteenth & $(72 \quad, \quad) \quad \ldots \ldots . . .$. & $98 \cdot 37$. & 0.56 & $97 \cdot 8 r$ \\
\hline
\end{tabular}

In this table, again, the range of figures for the eighteenth century largely surpasses that for the seventeenth century, and still 
more considerably that for the nineteenth, in which century both the highest and the lowest figures present a striking contrast to those of the two earlier centuries.* But the small figure $(0.56)$ or barely $I$ in 2,000 deaths from all causes, does not fully represent the low rate of mortality from small pox which took place in the year 1875. For the lowest figure $(2 \cdot 98)$ of the seventeenth century occurred in the year 1666, or that which followed the Great Plague, and coincided with the Great Fire. The immense mortality from the plague, the dispersion of a large fraction of the population, and the fire that destroyed so large a portion of the city, combined to reduce the possible victims by that disease, and the deaths from small pox, to the low figure of 2.98 per 1,000 ; the ratio of the previous year having fallen under the influence of the first two causes to the figure of 6.73 . So that the ratio of 0.56 represents for the present century a minimum mortality altogether without precedent.

\section{The Frequency of the Epidemics of Small Pox.}

Another question of interest which the returns given in Table I of the Appendix enable us to answer is the frequency of the occurrence of epidemics of small pox. If we still define an epidemic of that disease as an outbreak numbering 100 in $\mathrm{I}, 000$, or 10 per cent., we obtain the results embodied in the following table. If we count the several intervals between the epidemics both for the seventeenth and eighteenth centuries (for there have been no such epidemics in the nineteenth) we get the following figures :-

\section{TABLE IV.}

\begin{tabular}{|c|c|c|}
\hline \multirow{2}{*}{ Length of Interval. } & Seventeenth Century. & Eighteenth Century. \\
\hline & \multicolumn{2}{|c|}{ Number of Intervals. } \\
\hline 1 & 2 & 12 \\
\hline 2 & 2 & 6 \\
\hline 3 & 1 & 4 \\
\hline 4 & $\circ$ & 1 \\
\hline 5 & I & \multirow{2}{*}{2} \\
\hline 6 & I & \\
\hline $7 \quad$ & $\circ$ & 0 \\
\hline 8 & \multirow{2}{*}{ I } & \multirow{2}{*}{$\begin{array}{l}0 \\
1\end{array}$} \\
\hline 9 & & \\
\hline Total intervals.. & 8 years & \multirow{3}{*}{$\begin{array}{l}26 \text { years } \\
59 " \\
2 ”\end{array}$} \\
\hline$"$ length of same & \multirow{2}{*}{$\begin{array}{rl}30 & " \prime \\
4 & "\end{array}$} & \\
\hline Approximate average interval ......... & & \\
\hline
\end{tabular}

From this table then it appears that, still reckoning the epidemic of small pox at 100 in 1,000 , or 10 per cent., the intervals of freedom

* The figures for the shorter periods of thirty and forty years, as well as those for the three centuries, are given in full in Table II of the Appendix. 
range from one to eight years in the seventeenth century, and from one to nine years in the eighteenth century, the number of intervals having been 8 in the seventeenth, and 26 in the eighteenth, and the length of interval, or period of freedom, being a near approximation to four years in the seventeenth and two years in the eighteenth.

Here I pause for a moment to gather up the lessons taught by the three tables submitted up to this point. They teach us that while no epidemic of the standard assumed has taken place in this the nineteenth century, such epidemics were of frequent occurrence in the seventeenth and still more frequent in the eighteenth centuries; that this disparity shows itself very decidedly in such epidemics as exceeded 150 per 1,000; that the least ratio in any year of the eighteenth century did not fall nearly so low as in the century preceding and following; and that the intervals of freedom from epidemics was only half the length of those in the seventeenth century.

I may add that in three instances in the eighteenth century, but not once in the previous century, the epidemics exceeded one year in duration. The years in question were 1759 and 1760,1762 , 1763 , 64, and 65, and 1774 and 1775. I append the figures for these three periods :-

1759 and 1760 . I32:42, 110.28.

' $62,63,64$, and $65.104 \cdot 19,136 \cdot 98,102^{\circ} 66,107 \cdot 53$.

'74 and 75. 188.70, 138.10 .

One more comparison it occurs to me to make. The deaths from all causes in the seventeenth, eighteenth, and first thirty years of the nineteenth centuries present in many instances the same, or nearly the same, totals. When this happens I compare with these figures the deaths by small pox in the three centuries, with the results shown in the following table:-

\section{TABLE V.}

\begin{tabular}{|c|c|c|c|c|c|}
\hline \multicolumn{3}{|c|}{ Deaths from all Causes. } & \multicolumn{3}{|c|}{ Deaths by Small Pox. } \\
\hline Seventeenth Century. & $\begin{array}{l}\text { Eighteenth } \\
\text { Century. }\end{array}$ & $\begin{array}{l}\text { Nineteenth } \\
\text { Century. }\end{array}$ & $\begin{array}{l}\text { Seventeenth } \\
\text { Century. }\end{array}$ & $\begin{array}{l}\text { Fighteentl } \\
\text { Century. }\end{array}$ & $\begin{array}{l}\text { Nineteenth } \\
\text { Century. }\end{array}$ \\
\hline 23,202 & 23,202 & - & 1,560 & 2,382 & - \\
\hline $2,3,222$ & 23,230 & 23,524 & 2,496 & 2,498 & 736 \\
\hline 22,609 & 22,612 & $22,2,98$ & 1,062 & 2,188 & 616 \\
\hline 21,053 & 21,057 & 21,026 & 689 & 1,614 & 1,299 \\
\hline 21,730 & 21,800 & 21,709 & 1,967 & 1,024 & 598 \\
\hline $2,1,20 I$ & 21,198 & - & 2,507 & 1,943 & - \\
\hline 20,198 & 20,213 & 20,237 & 1,465 & 1,568 & 725 \\
\hline 19,067 & 19,048 & 19,283 & 1,678 & 1,728 & 638 \\
\hline 18,732 & 18,760 & 18,865 & 359 & 1,747 & 604 \\
\hline 17,504 & 17,576 & 17,565 & 853 & 1,273 & 1,685 \\
\hline Totals .... 208, 518 & 208,696 & 一 & 14,636 & 17,965 & $6,90 \mathrm{I}$ \\
\hline Averages $20,85^{1}$ & 20,869 & 一 & $1,46_{3}$ & 1,796 & 863 \\
\hline
\end{tabular}


These instances, which have been chosen from others solely on account of the near approximation of the figures in the three centuries, show a less average difference than does a collection of sixteen instances. This larger number of cases gives an excess for the eighteenth century of 524 deaths by small pox.

It appears then that out of the same number of deaths from all causes occurring in the two centuries, those by small pox form a larger increment in the eighteenth than in the seventeenth century; while the figures for the nineteenth century show a very remarkable falling off in the deaths by small pox relatively to the deaths by all causes. The average figure, which is 1,463 and 1,796 respectively for the seventeenth and eighteenth centuries, is only 863 for the eight years which admit of being brought into comparison with the figures for the ten years of those earlier centuries.

I now take in hand the epidemic measles which, as I have already stated, figures on the returns for the same long period of time as small pox itself, and shares with it signs and symptoms easy to recognise and not subject to any great amount of doubt or misapprehension.

\section{Epidemics of Measles at Different Periods.}

In tracing the column of figures which represents the deaths by measles year by year, we nowhere encounter the high figures which mark the epidemics of small pox. The deaths by measles in no year reach 100, and once only the high level of 93. Where, in the columns of small pox, 100 met the eye, such figures as 20 meet it in measles. Hence for no other or better reason than that upon which I have acted in the case of small pox, I now act in the case of measles, and assume 20 as the epidemic figure, with what results the following table will show:-

\begin{tabular}{|c|c|c|}
\hline \multicolumn{3}{|c|}{ TABLE VI. } \\
\hline $\begin{array}{c}\text { Arrangement by Periods of Thirt } \\
\text { Years. }\end{array}$ & & $\begin{array}{c}\text { Arrangement by Periods of Forty } \\
\text { Years. }\end{array}$ \\
\hline $1647-76$ & 2 & $1647-86 \ldots$ \\
\hline 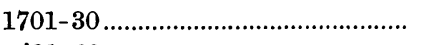 & $\circ$ & 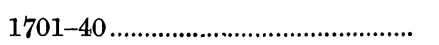 \\
\hline '31-60 & 3 & ${ }^{\prime} 411-80 \ldots . .$. \\
\hline 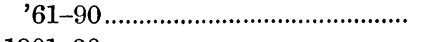 & 5 & \\
\hline 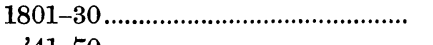 & 26 & $1001-31$ (tnirty-one years) ............. \\
\hline $41-70 \ldots \ldots$ & Io & $41-80$ \\
\hline
\end{tabular}

Arrangement by Centuries.

Seventeenth century (forty-eight years)

Eighteenth " (one hundred ")

Nineteenth $"$ (seventy-two $"$ ) ..................... 5 5

The figures in this table display a striking contrast with those of Table I. They show, it is true, more epidemics of measles in 
the eighteenth century as of small pox; but a further increase in the nineteenth century, in which epidemics of small pox ( 100 per I,, 00 deaths being taken as the standard) wholly disappear. But in the case of measles, as of small pox, I will assume both lower and higher figures as measures of an epidemic, as is done in the table which follows :-

TABLE VII.

\begin{tabular}{|c|c|c|c|}
\hline \multirow[b]{3}{*}{10 ner 1000 and lesg than 75} & \multicolumn{3}{|c|}{ Centuries. } \\
\hline & Seventeenth. & Eiglteenth. & Nineteenth. \\
\hline & 3 (48 yrs.) & 9 (100 yrs.) & 2 (72 yrs.) \\
\hline $20 \ldots \ldots \ldots \ldots$ & 0 & 10 & $15 \ldots$ \\
\hline 25 ............... & 0 & 4 & 17 \\
\hline 25 per $\mathrm{r}, 000$ and upwards & & & $34 "$ \\
\hline 10 and upwards ................... & 5 & 28 & 68 \\
\hline
\end{tabular}

These figures confirm and strengthen those of the preceding table. With the exception of the first line, which places the epidemic figure at 10 per 1,000 and under 15 , the rest are in harmony. Making allowance for the different number of years available for comparison in the three centuries, the deaths by measles show a progressive and very considerable increase; and if reduced to an equal standard of years, the figures for 10 per 1,000 and upwards would approximate to 10, 28, and 90. Let us now see what we can glean from a statement of the highest and lowest figures, and the range of the figures as shown in

TABLE VIII.

\begin{tabular}{|c|c|c|c|c|}
\hline \multicolumn{2}{|r|}{ Centuries. } & \multirow{2}{*}{$\begin{array}{c}\text { Maximum. } \\
93^{\circ} 00\end{array}$} & \multirow{2}{*}{$\frac{\text { Minimum. }}{0.05}$} & \multirow{2}{*}{$\frac{\text { Range. }}{92 \cdot 95}$} \\
\hline Seventeenth & entury ................ & & & \\
\hline Eighteenth & ", & $52 \cdot 80$ & $0 \cdot 24$ & $52^{2} \cdot 5^{6}$ \\
\hline Nineteenth & 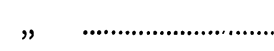 & $69^{\circ} 45$ & $6 \cdot 35$ & $6_{3} \cdot 10$ \\
\hline
\end{tabular}

These figures teach us that while deaths by measles in the seventeenth century rose to a higher figure in one year of the fortyeight, and fell to a lower figure than in the subsequent centuries, the nineteenth century was marked by higher figures than the eighteenth, but not by figures falling so low as happened in either of the foregoing centuries.

The broad lesson to be learnt from this table is that deaths from measles, when compared with deaths from all causes, have reached a higher lerel in the nineteenth centary than in the 
eighteenth. This, as it will have been seen, is the reverse of what has happened with small pox.

What has been already said of the low level to which the deaths by small pox fell in the years 1665 and 1666, is true also of measles. The deaths by measles were very few in those years, and doubtless for the same reasons.

There is another disease which may be fairly brought into comparison with small pox and measles, as being, like them, easy to recognise, and, like them, contagious and epidemic, and respecting which, for many years, both of the eighteenth and nineteenth centuries, we find the annual returns of deaths in Marshall's tables. I mean whooping cough. The first entry of deaths from this disease is found under the year 1776, and the last under 1831. The deaths from 1841 to 1881 inclusive are given in the annual summary of the registrar-general. The facts in full will be found in Table III of the Appendix, the summary of results in the table which follows :-

TABLE IX.-Deaths by Whooping Cough (1740 to 1881).
Number of Epidemics (25 per 1,000 taken as an Epidemic).

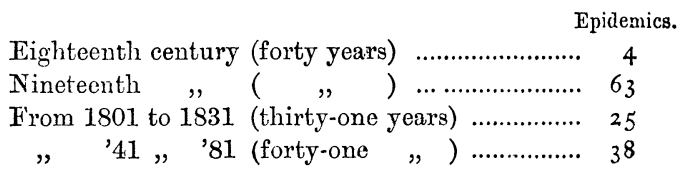

The figures in this table, like those relating to measles, show an increase in the ratio of deatbs from 4 in the $\mathrm{I}, 000$ in the eighteenth century to 63 in the 1,000 in the nineteenth, and from 25 per 1,000 in the first thirty years of the nineteenth century, as compared with the forty years ending 1881. If we add a third to the thirtyone years, we bring the figure of deaths up to 33 , which is less by 5 than the figure for the later period. It follows, therefore, that whooping cough, like measles, and unlike small pox, exhibits an increased number of epidemic outbreaks in the nineteenth century.

The figures which show the maxima and minima for the same periods of time harmonise with this the number of epidemics. This is shown in

TABLE X.

\begin{tabular}{|c|c|c|c|}
\hline Centuries. & Maximum. & Minimum. & Range. \\
\hline Eighteenth century & 27.79 & $2 \cdot 23$ & $25^{\circ} 5^{6}$ \\
\hline Nineteenth , & $68 \cdot 59$ & $16 \cdot 33$ & $52 \cdot 26$ \\
\hline
\end{tabular}


Taking the figures of these two tables together, we arrive at the conclusion that the ratio of deaths by whooping cough to deaths by all causes increased during the present century. The application of this fact, as of the facts relating to measles, to the question of the efficacy of vaccination will be presently apparent.

\section{Bearing of Previous Facts and Inferences on the Effects of Inoculation and Vaccination.}

Having set forth the inferences to be drawn from the records of two hundred and fifty years in relation to small pox as an epidemic malady, and those that relate to measles and whooping cough as being of minor importance, I now proceed to inquire whether those records enable us to throw any light upon the effects of inoculation and vaccination.

I. Inoculation.-Inoculation, as a means of imparting to a larger or smaller section of the population a form of small pox entailing a low rate of mortality, in lieu of exposing the whole population to the risk of catching the natural disease with its much higher death-rate, was first practised in England in 1722, and, for reasons which it is not necessary here to state, made its way but slowly into popular favour. Hence Dr. Gregory, with only an approximation to the trath, speaks of the interval from 1711 to 1740 as one in which there was no inoculation. Modern writers, looking back to the eighteenth century, and taking note of the deaths and death-rates from small pox, have been divided in opinion as to its ultimate effect, on the mortality. One set of writers, well represented by Sir Gilbert Blane, upheld the doctrine that inoculation had on the whole been mischievous; while another set, worthily represented by Dr. Gregory, held that inoculation had lessened the mortality from small pox. Having occasion to treat of the effects of inoculation in my work on Public Health,* I gave my adhesion to the favourable view put forth by Dr. Gregors, and justified it by figures, to which I shall presently advert. But I will first refer to the facts bearing on this question which have already been established in this paper-facts, be it understood, resulting from a comparison of the figures of the seventeenth with those of the eighteenth century. These facts in general terms, divested of figures, may be stated as follows :-

1. Epidemics of small pox were more frequent in the eighteenth sentury than in the seventeenth.

2. The epidemics, taken one with another, were more severe in the eighteenth than in the seventeenth century.

3. The epidemics of the eighteenth century occurred at shorter intervals than those of the seventeenth.

* “Public Health.” Lecture viii, p. 205. 
4. Certain epidemics of the eighteenth century lasted more than one year, but none of the seventeenth century.

5 . When years of equal, or nearly equal, mortality from all causes occurring in the seventeenth and eighteenth centuries are compared, deaths by small pox are found to furnish a larger contingent of deaths in the eighteenth century than in the seventeenth,

These facts afford a strong presumption that small pox, for some reason or other, was a more severe malady in the eighteenth century than in the seventeenth. But the presumption in favour of inoculation having been the cause of an increased mortality is less strong. To justify this inference, or to prove it unsound, we must bear in mind that inoculation did not come into play till towards the end of the first quarter of the eighteenth century, nor into general use till the last quarter. So that if we begin by comparing the ratio of deaths by small pox to the total deaths in the forty years of the seventeenth century from 1647 to 1686, with the corresponding forty years of the eighteenth, we shall have a series of years in the eighteenth century during which the practice of inoculation may be safely assumed to be progressively on the increase, though it had not yet attained its highest point of development. The table which follows presents the principal results of this comparison :-

TABLE XI.

\begin{tabular}{|c|c|c|}
\hline \multirow[b]{3}{*}{$\begin{array}{l}\text { Epidemics of small pox (100 to } \mathrm{r}, 000) \\
\text { Maxima (in round numbers) } \\
\text { Minima ( } \\
\text { Intervals between" epidemics (approximate) } \\
\text { Epidemics exceeding one year }\end{array}$} & \multicolumn{2}{|c|}{ Centuries. } \\
\hline & $\begin{array}{c}\text { Seventeenth } \\
(1647-86) .\end{array}$ & $\begin{array}{c}\text { Eiglteenth } \\
\text { (1747-86). }\end{array}$ \\
\hline & $\begin{array}{r}9 \\
124 \\
3 \\
4 \\
-\end{array}$ & $\begin{array}{r}17 \\
173 \\
15 \\
2 \\
2\end{array}$ \\
\hline $\left.\begin{array}{l}\text { Ten equal, or nearly equal, deaths from all } \\
\text { causes-average deaths from small pox .... }\end{array}\right\}$ & 1,633 & 2,127 \\
\hline
\end{tabular}

It will be seen that all the figures of this table agree in representing small pox as more severe in the eighteenth century at a time when inoculation was being largely practised, than in the seventeenth when the practice was unknown.

But Dr. Gregory, who thought, in opposition to Sir Gilbert Blane, that small pox proved less fatal in that part of the eighteenth century when inoculation was being practised, justified his opinion by comparing the deaths by small pox in the three periods of twenty-nine years, ending respectively with 1740, 1770, and 1800; the first period being one in which, as he states somewhat incorrectly, there was no inoculation, the second period, one in which 
inoculation was coming into general use, and the third, one in which it was almost universal. Dr. Gregory obtained, as the result of this comparison, the figures (being the totals of the deaths) 65,385 , 63,308 , and 57,268 , showing an ultimate saving of no less than 8,1 I 5 lives. I waive the objection which may be made to this division, namely, that the first period of twenty-nine years ending 1740 was not free from the practice of inoculation, and arrange my own figures in a tabular form.

TABLE XII.

\begin{tabular}{|c|c|c|c|}
\hline & $\begin{array}{l}\text { First Period, } \\
\text { ending } 1740 . *\end{array}$ & $\begin{array}{l}\text { Second Period, } \\
\text { ending } 1770 . *\end{array}$ & $\begin{array}{l}\text { Third Period, } \\
\text { ending 1800.* }\end{array}$ \\
\hline Epidemies of small pox & 7 & II & 11 \\
\hline 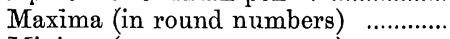 & 125 & 173 & 184 \\
\hline Minima ( $\quad "$ & 47 & 40 & 15 \\
\hline $\left.\begin{array}{c}\text { Intervals between epidemics (ap- } \\
\text { proximate) }\end{array}\right\}$ & 3 & 2 & 2 \\
\hline Epidemics exceeding one year.............. & - & 2 & 1 \\
\hline Aggregate of deaths by small pox .... & 60,391 & 61,398 & 54,958 \\
\hline
\end{tabular}

* 1711-39, 1741-69, and 1771-99 all inclusive.

The figures of the first and third columns of this table confirm Dr. Gregory's statement, though the aggregates differ from his, and the figures of the second column show an increase. The totals, as stated by him, are larger, but his tables and mine agree in showing an ultimate saving of life. This falling off of the numbers takes place, though the epidemics are more frequent and more severe in the second and third periods. But, on the other hand, the minima fall much lower.

I know that Dr. Gregory, with whom I was personally acquainted, was moved by these results to advocate a twofold protective procedure in the shape of raccination followed by inoculation.

I may add that when I adopt the division which I have advocated into three decades, the first representing small pox not modified by inoculation, ending 1719 ; the second small pox modified by inoculation in partial use, ending 1749 ; and the third corresponding to the large and general practice of it, ending 1799, I obtain from my tables the following figures, $21,228,20,029,17,785$, showing an ultimate saving of 3,443 lives. I had calculated the numbers for the three periods, when reduced to the uniform standard of a million inhabitants, at $3 \mathrm{I}, 4 \mathrm{I} 6, \mathbf{2 8 , 2 8 2}$, and 22,863 .

Doubtless in the eighteenth century there were influences at work tending strongly to counteract any injurious influence which inoculation may be presumed to have exerted by spreading the disease which it mitigated. There was the progressive rooting out 
of small pox from one of its centres of distribution, our prisons; some improvement, not easy to define or measure, in the sanitary condition of our town population, and, in the last years of the century the abstraction of large numbers of our adult males to supply our armies and fleets during the early years of the war with France-an abstraction which must have largely diminished (as did the deaths and lessened population caused by plague in the year $1665)$ the possible victims of small pox. Vaccination, though introduced in 1796, had not yet been brought into play upon more than a few thousand persons in the years of the century that remained. If we take these possible causes of diminished mortality fairly into account, we shall probably arrive at the conclusion that the practice of inoculation by effecting a large saving of life among those on whom it was brought to bear, did in a great degree counteract the currency given to small pox among those whom it left alone.

II. Vaccination.-Is vaccination a preventive of small pox? To this question there is, there can be, no answer except such as is couched in the language of figures. The response must issue from a comparison of the deaths from small pox in a period prior to the introduction of vaccination with the deaths from the same disease in some period subsequent to its introduction, and, as the alleged preventive is known to have come into play by degrees, and to have taken effect on an ever increasing section of the population, the figures may be expected to harmonise with that known condition of things. They may also be expected to form an exception to the rule of all those diseases to which no similar method of prevention has been applied. For if they did not display such difference, but simply shared with them the common property of progressive decline, the diminishing mortality might be explained by some sanitary improvements common to them all. The figures, therefore, which present the ratio of deaths by small pox to deaths by all causes, ought either to stand alone in the extent and progressiveness of their fall, or, if they resemble any other epidemic diseases in this respect, they should so far excel them as to admit of division into two parts, of which the one should be taken as the results of sanitary improvements which have lessened the mortality of several diseases in common, and the other should stand alone-a progressive reduction peculiar to itself. I shall presently make application of these tests, but before doing so, shall revert to certain facts established in the earlier part of this paper.

1. The first in order of these facts is the entire absence in the present century of epidemics of the intensity represented by the ratio of 100 deaths by small pox to 1,000 deaths from all causes, though one such epidemic occurred in the year 1800, and several in all periods of the eighteenth as of the seventeenth century. 
190

180

170

160

150

$18 T H$

CENTURY 100

140

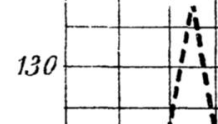

120 100 (1)

i.
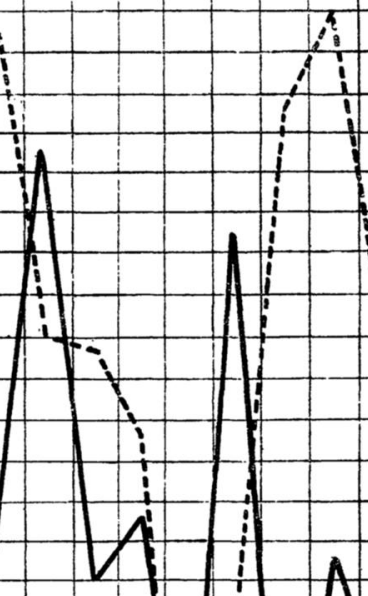

CENTURY

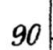

80

70

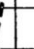

50

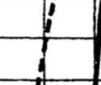

i.

1
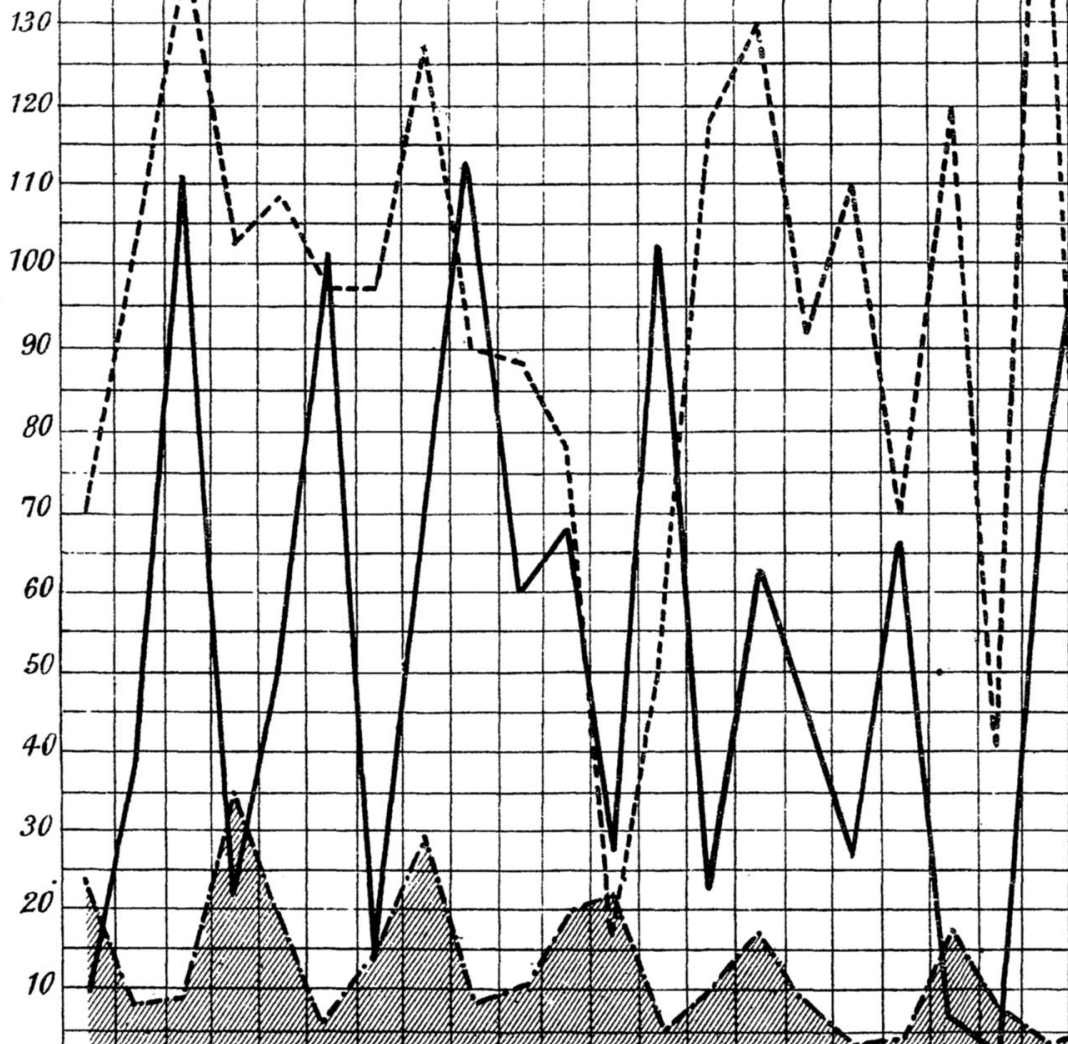
2. The marked excess of epidemics in the eighteenth century, when compared with the seventeenth century, is a fact of importance in its bearing on the question in hand; for it shows that small pox had not, even up to the close of that century, undergone any considerable abatement. Small pox, so to speak, had witnessed and survived the extinction of the plague, of which the last case is recorded in 1680, and the omission from the bills of mortality of such fatal maladies as the "Parish Infection."

3. That the small pox up to the close of the eighteenth century had undergone no considerable abatement, is further proved by the fact that some of the most severe epidemics took place in the last twenty years of the century ( 169 in the 1,000 in 1781, 184 in the $\mathbf{r}, 000$ as late as 1796). This last epidemic was the worst on record, I 73 in the 1,000 being the only one on the same scale, and this occurred in 1752.

4. The lowest figures, too, are not without instruction, as bearing upon the efficacy of vaccination. The lowest figure recorded during the seventeenth century is $2.9^{8}$ per $\mathrm{r}, 000$, in the year following the great plague, whereas the lowest recorded figure in this nineteenth century, during the prevalence of vaccination, is 0.56 , or less than one-fifth of the low figure already accounted for by the incidents attending and following the great plague and great fire of London.

5 . The lessons thus tanght us in regard to the prevalence of small pox in the eighteenth century are rendered more impressive by the fact that epidemics were more frequent, or, in other words, separated on the average by shorter intervals of comparative freedom, in that century than in the seventeenth. The epidemics of the eighteenth century occurred once in two years, those of the seventeenth once in four.

6. In the eighteenth century again, and in that alone, were the epidemic outbreaks of small pox of more than one year's duration. Twice they extended to two years, once to four.

7. If we compare years of equal mortality from all causes in the seventeenth and eighteenth centuries, we find deaths by small pox more numerous on the average in the eighteenth century than in the seventeenth, and much less numerous in the nineteenth than in either of the previous centuries.

8. If we compare deaths by measles with those by small pox we find them marked by this difference, that while there was no epidemic of small pox in the nineteenth century, there were several epidemics of measles, and that the mortality from measles rose to a higher level in the nineteenth than in the eighteenth century, being the reverse of what happened with small pox.

9. So also of the whooping cough. It caused a much higher

VOL. XLV. PART III. 
proportion of the total deaths in the nineteenth than in the eighteenth century, and therefore strengthens the lessons taught us by the measles.

Under the foregoing headings I have marshalled a series of statements which, if I am not mistaken, bespeak for the further examination of this subject a serious and sustained attention.

I shall, I think, make my meaning plainer if, in what remains of this paper, I adopt the standard of 100,000 instead of 1,000 , thus avoiding the use of decimals. I shall also add to the confidence which the figures I have already employed may have produced if I place side by side with them, as I do in Table IV of the Appendix, the ratios of deaths by small pox and by measles to roo,000 of the living population, drawing from these figures such inferences as they may seem to warrant.

I have already stated that in no year of the present century has the ratio of deaths by small pox to deaths by all causes attained the high level of 100 and upwards so frequent in the last years of the eighteenth. If we count the year 1800 as the last of the eighteenth century, these high ratios ended with that year, in which the ratio of deaths by small pox was 10,443 per 100,000. Twice only in the seventy-two years of the present century did the ratio approximate at all closely to that high figure. These were the years 1805 and 1871, when the figures were 9,592 and 9,837 respectively. For the past year 1881, they were 2,924. In fifty-eight years then, we had two epidemics approaching in severity the mildest of the old epidemics of the seventeenth and eighteenth centuries. In thirtyseven years of the seventeenth century we had nine such epidemics : in fifty-five years of the eighteenth we had twenty-four. Between these two years of maximum mortality much lower figures present themselves, especially after the year 1841, when the returns of the registrar-general may be said to have assumed a permanent form. The years following this date, like the years of the earlier centuries, are marked by frequent fluctuations in the ratios of deaths from small pox, which fluctuations contrast strongly with the comparative steadiness of the figures for measles, and for whooping cough, as will be seen on reference to Tables I and III in the Appendix. But these fluctuations of the last forty years were not only frequent in occurrence, they were great in amount, falling so low in 1875 as 56 deaths from small pox in 100,000 from all causes.

The value of facts of this order can only be ascertained by comparison with others relating to the same disease at earlier periods and under different circumstances, and to other diseases at the same period.

Now the first question that suggests itself is this-whether the ratio of deaths by small pox to deaths by all diseases ever fell so 
low in the seventeenth and eighteenth centuries. The answer is in the negative. The minimum of the seventeenth century occurred, as I have already stated, in the year 1666, under circumstances altogether exceptional-circumstances which reduced the deaths by measles in a like degree, and the deaths from all causes to an unusually low amount. If we exclude this low figure of 298 and that of the previous exceptional year 673, we find the minimum to have occurred in the year 1647, when it was 1,008 . On the other hand, this low figure of small pox mortality in the nineteenth century occurred in a year of very high mortality from all causes.

But the significance of this low ratio of 56 per 100,000 is greatly inereased if we compare it with the lowest ratio of the eighteenth century. Twice, and twice only in the hundred years, did the minimum sink so low as $\mathrm{I}, 500$ or thereabouts. The first occasion was in 1702, when the ratio was 1,596 in 100,000, and the other in 1772, when it was 1,532 . If we take the last figure as the lowest of the century, we have the following contrast :-

17th century, year 1647, r,008 deaths by small pox in 100,000 from all causes.

18th $\quad 1772$, ז, 532

19th $\quad 1875, \quad 56$

"

"

So that in a year of this century of exceptionally high mortality from all causes, the deaths by small pox fell to 56 in 100,000, or exactly an eighteenth of the minimum of the seventeenth century, and about $I$ in 27 of the minimum of the eighteenth century.

If, again, we deal with the highest instead of the lowest figures, we get the following results :-

17th century, year 1681, 12,440 deaths by small pox in 100,000 from all causes. 18th " $\quad 1796,18,394$ 19th $\quad, \quad 1871,9,837$

"

Hence it appears that the maximum ratio of deaths by small pox in the nineteenth century, the epoch of vaccination, very little exceeded half the maximum of the eighteenth, while the minimum fell to the curiously low figure of one twenty-seventh of that recorded in the previous century. The contrast afforded by the high figures of the seventeenth and eighteenth centuries and the low figures of the nineteenth is well shown by the annexed curves.

These contrasts will appear the more significant if I compare them with what happened in the cases of measles and whooping congh.

The figures for measles in the three centuries were as follows :-

The maximum, which was 9,300 in the 100,000 deaths from all causes in the seventeenth century, fell to 5,280 in the eighteenth, 
to rise to 6,945 in the nineteenth, while the minimum rose from 5 in the 100,000 in the seventeenth century to 52 in the eighteenth, and 635 in the nineteenth. So that the movement, if I may so express myself, from the eighteenth century to the nineteenth was one of increase, both for maxima and minima, in the case of measles, of decrease in the case of small pox.

In the case of whooping cough again, the maximum in the eighteenth century, which from the year 1740 to 1800 was 2,779 per 100,000 deaths, rose to 6,859 in the nineteenth century, while the minimum rose from 223 to 1,633 , again the very reverse of what happened with small pox.**

If then it were to be alleged that the remarkable fall in the maximum mortality from small pox, and still more remarkable fall in the minimum, are attributable not to vaccination but to miscellaneous sanitary reforms and improvements, we are furnished with a conclusive answer in the figures for measles and whooping cough. How happened it, it may well be asked, that the same sanitary reforms and improvements which so greatly lowered the mortality from small pox, whether we measure it by the maxima or the minima, acted on measles and whooping cough in the opposite sense, raising in lieu of lowering their respective death-rates?

An advocate of vaccination might take his stand upon thèse numerical contrasts, and treat any further inquiry in the same direction as mere waste of time; but a critical inquirer after truth might seek to push the investigation to its utmost limits by bringing forward all the diseases which may fairly claim to be brought into comparison with small pox, and he might further insist on making use of any existing standard of comparison other than the ratio of deaths to deaths. This cautious and sceptical method I now propose to adopt. I shall first present a tabular analysis of the facts relating to small pox, using the ratio of deaths to deaths, and then make a final comparison of deaths by small pox to the living population, placing this comparison side by side with a similar comparison for other diseases which, like small pox, may be presumed to have been favourably affected by sanitary reforms and movements. The following table presents at one view the first order of facts, with which I have hitherto been dealing throughout this inquiry, taking short periods of five years for purposes of comparison, and appending a column of notes of the chief incidents of this century which may be supposed to have exercised an influence on the mortality :-

* The years of the maxima for measles were 1648, 1771, and 1808; of the minima, 1675, 1704, and 1809; the years of the maxima for whooping cough were 1796 and 1831 ; of the minima, 1744 and 1808. 
TABLE XIII.

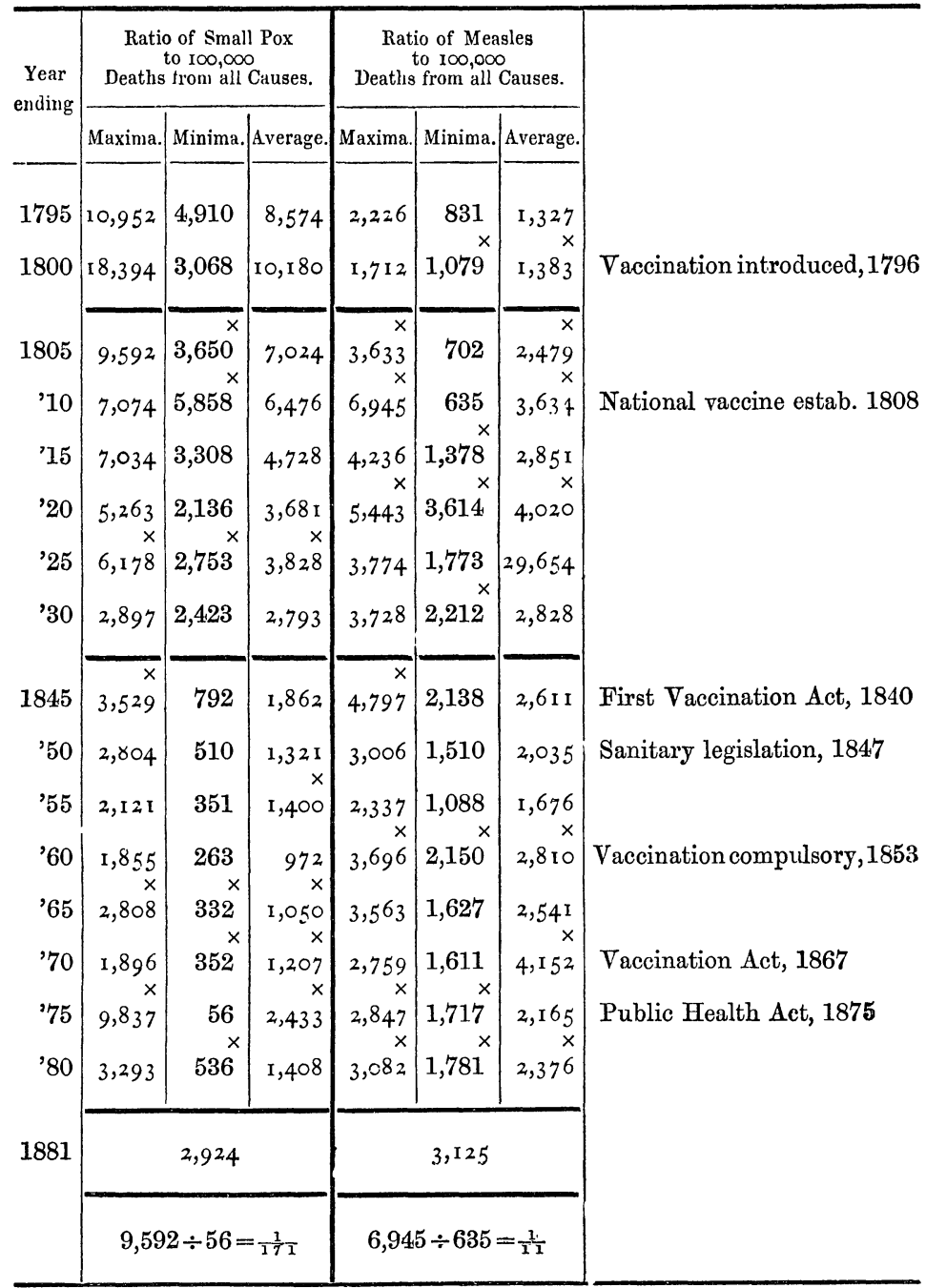

In this table the following facts are made apparent:-

1. The high mortality from small pox which prevailed in the five years ending 1800 .

2. The progressive lowering of the mortality from small pox during the first six quinquennial periods prior to the epoch of sanitary reform, as shown in the three columns of maxima, minima, and average.

3. A like progressive lowering of the mortality coincident with 
sanitary reforms and vaccine legislation during the eight quinquennial periods ending with the year 1880.

4. Several interruptions in the progressive decline in all the columns, and a recurrence of the high figure which stands at the head of the table under the quinquennium ending 1805, in the quinquennium ending 1875, after the long interval of fifty-eight years.

The general broad result of the table is a great decrease of mortality, both in the period of thirty years during which vaccination being received with public favour, obtained the support of the State in the form of the national vaccine establishment founded in the course of the second quinquennium, and in the longer period of forty years during which vaccination was first made gratuitous (1840), and then compulsory (1853).

In the first period of thirty years there was no sanitary legislation to which to attribute the decreased mortality from small pox, and during this period the deaths by measles tended rather to increase than diminish, while the deaths by small pox fell, on an average, from 7,024 to 2,793 , being a decrease of $4,23 \mathrm{I}$, or much more than half the highest figure. In the second period of forty years the ratio fell from 2,793 (the lowest average figure of the first period) to 1.408 , being a decrease of somewhat less than a half. In this second period the decrease in the case of measles was very small. But the most striking result of the table is seen if we compare the highest figure recorded during the first quinquennium ending 1805 with the lowest recorded in that ending 1875. The interval between the two is that which separates $9,59^{2}$ from 56 , or 9,536. The minimam compared to the maximum is as $I$ to $I 7 I$. On the other hand, the minimum for measles compared with the maximum for that disease $(635$ and 6,945$)$ is less than $\mathrm{I}$ to $\mathrm{I}$. So that the reduction in the case of small pox was about seventeen times as great as the reduction in the case of measles.

I now extend this comparison from small pox and measles to small pox and the other epidemic maladies brought into comparison with it in the pages of the registrar general, with what results will be seen in Table XIV. 
1882.]

Years of Small Pox in London.

\begin{tabular}{|c|c|c|c|c|}
\hline \multirow{3}{*}{ : } & 岁案 & $m \times \underset{m}{m}$ a $n \times m$ & \multirow{3}{*}{ s } & \\
\hline & 过 & $4 \times 5 \times 0$ a $4 \times 1 \times n$ & & \\
\hline & 离 & 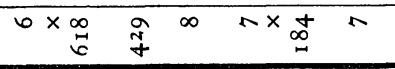 & & \\
\hline \multirow{3}{*}{ 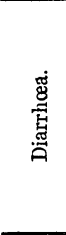 } & 岁案 & 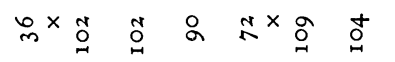 & \multirow{3}{*}{ ○ } & \multirow{3}{*}{ 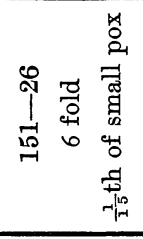 } \\
\hline & 言峘 & 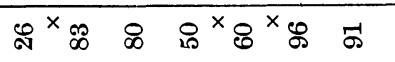 & & \\
\hline & 䊑 & 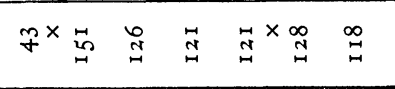 & & \\
\hline \multirow{3}{*}{ 岕 } & 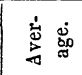 & 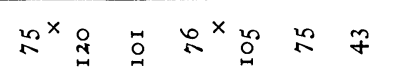 & \multirow{3}{*}{$\vec{m}$} & \multirow{3}{*}{ 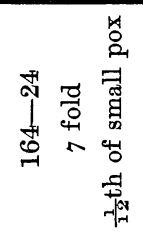 } \\
\hline & 送 & 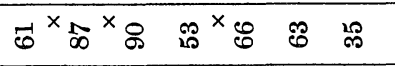 & & \\
\hline & 密 & 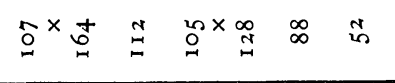 & & \\
\hline \multirow{3}{*}{ 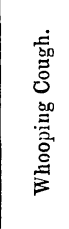 } & 岀密 & $\vec{a} \infty^{x} \alpha \infty^{x} \vec{a} \infty \infty^{\infty}$ & \multirow{3}{*}{ in } & \multirow{3}{*}{ 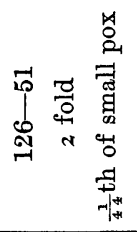 } \\
\hline & 量 & 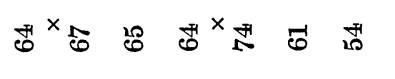 & & \\
\hline & 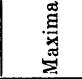 & 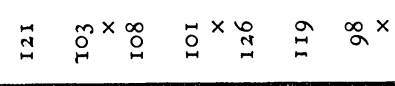 & & \\
\hline \multirow{3}{*}{ 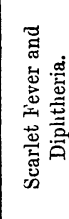 } & 㞻宫 & $a^{x} a^{x} a^{x} b_{0}^{x}+\underset{m}{a} \vec{\pi}^{x}$ & \multirow{3}{*}{$\stackrel{m}{m}$} & \multirow{3}{*}{ 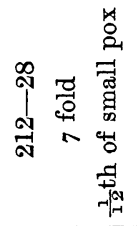 } \\
\hline & 言兽 & 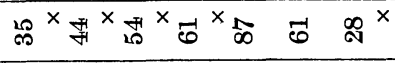 & & \\
\hline & 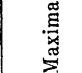 & 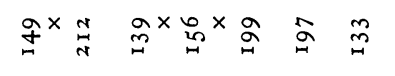 & & \\
\hline \multirow{3}{*}{ 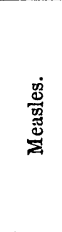 } & 离密 & 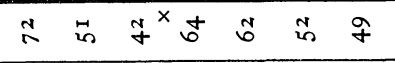 & \multirow{3}{*}{$\not 8$} & \multirow{3}{*}{ 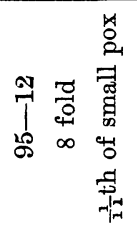 } \\
\hline & 常 & 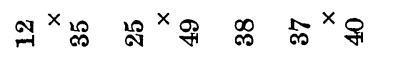 & & \\
\hline & 营 & $t^{x}{ }_{\infty}$ in $^{x} \infty_{\infty}^{x}$ 兄 $\approx t^{n}$ & & \\
\hline \multirow{3}{*}{ 产 } & 离案 & 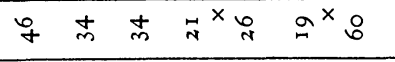 & \multirow{3}{*}{$\tilde{6}$} & \multirow{3}{*}{$\begin{array}{ll}1 & 0 \\
0 & 0 \\
\infty & 0 \\
\infty & 0 \\
\infty\end{array}$} \\
\hline & 皇题 & 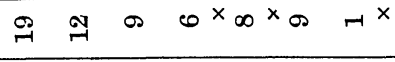 & & \\
\hline & 总 & $\underset{\infty}{\infty} \stackrel{\infty}{+} f^{x} a q^{x} \dot{q}^{x}$ & & \\
\hline & & 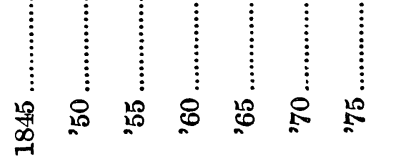 & 点 & 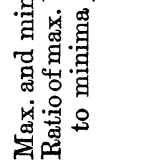 \\
\hline
\end{tabular}


The results of this table are very remarkable, and may be thus briefly summarised:-

1. The highest figure for small pox in any year is 89 per 100,000 persons living, the lowest, I for the same living population; so that the lowest figure is equal to one-eighty-ninth of the greatest number of deaths.

2. The highest figure for measles is 95 and the lowest 12 : showing a fall to one-eighth, or an eleventh part of the fall in the case of small pox.

3. The highest figure for scarlet fever and diphtheria is 212 and the lowest 28 : being a like fall to less than one-eighth, or, again, an eleventh part of the fall in the case of small pox.

4. The highest figure for whooping cough is 126 , the lowest $5 \mathrm{r}$ : being a fall to much less than a balf, or less than a forty-fourth of the fall of small pox.

5. In the case of fever the highest figure is 164 , the lowest 24 : being a fall to one-seventh, or a tifteenth of the fall in the case of small pox.

6. For diarrhoea the highest figure is 151 , and the lowest 26 : being a fall to a sixth, or a fifteenth of the fall in the case of small pox.

That I may not omit from the table a disease included in the columns of the registrar general, I give the figures for cholera, though, as a special exotic epidemic, it cannot be admitted to a comparison with the rest.

Taking then one epidemic malady with another, it appears that the mortality by small pox stands alone in the amount of reduction it has undergone during this century, the other epidemic maladies showing an abatement ranging from one-eleventh, twelfth, or fifteenth, to one forty-fourth of that higher amount. If we may assume that all these epidemic maladies shared with small pox the benefits conferred by the several sanitary reforms that have signalised the last half of this century, there still remains to be accounted for the remarkable difference between these figures. Vaccination is the concurrent force brought to bear on small pox, can we find any other to account for the difference? I think not; I can imagine no other.

But the remarkable epidemic of small pox which occurred in 1871 may be brought forward as an argument in favour of a desponding view of the preventive efficacy of vaccination, assuming vaccination to have been the cause of all the abatement that small pox has not shared with other maladies. Let us then examine this remarkable outbreak by the light thrown upon it by its surroundings.

In the first plase it should be observed that this outbreak stands 
alone in the long interval which separates it from any attack of like severity. The longest interval between epidemic and epidemic in the previous centuries was eight years or nine; but we must go back to the year 1805, a space of fifty-six years of recorded facts, to find such another. Let us take the two outbreaks, with the facts of the years that preceded and followed them, and note the differences, if any, between them. I present the figures in ratios to $I, 000$ deaths, and in round numbers.

\section{TABLE XV.-The Two Epidemics of the Nineteenth Century compared. 1805.

Before commenting on this curious contrast, I will deal in the same manner with the four great epidemics of the eighteenth century, which claimed as their victims upwards of 150 deaths by small pox in 1,000 deaths by all causes.

\section{TABLi XVI.}

1752.

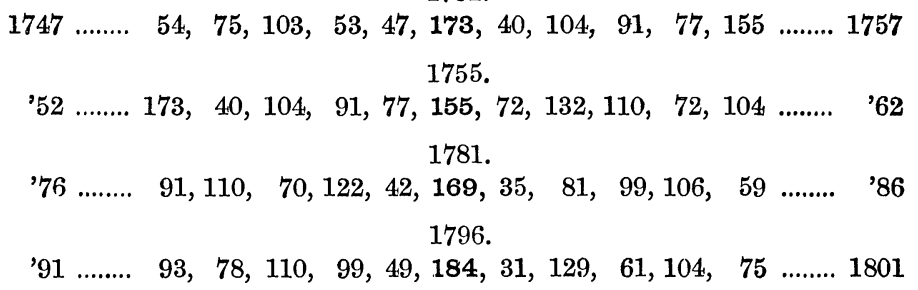

The following table will assist us in our comparison :-

Total of Deaths in
Five Years preceding.
332
485
435
429
359
61

$\begin{array}{cc}\text { TABLE XVII. } & \begin{array}{c}\text { Total of Deaths in } \\ \text { Five Years following. }\end{array} \\ 173(1752) & 467 \\ 155(' 55) & 490 \\ 169(' 81) & 380 \\ 184(' 96) & 400 \\ 96(1805) & 325 \\ 98(' 71) & 37\end{array}$

The figures in these three tables do but confirm each other. They agree in enforcing the same lesson. The most severe epidemics of the last century were preceded and followed by one year of a comparatively low mortality, these being in their turn preceded and followed by high figures in which one or two epidemics found place. The first epidemic of the present century, which could not have 
been greatì influenced by vaccination, presented somewhat similar figures; but the second epidemic (that of 1871) exhibited the most striking contrasts. For the years directly preceding and following not only display comparatively low figures, but some of the lowest figures to which the deaths from small pox have ever fallen are to be found in the groups of four years which preceded and followed these. The figures for the three years 1873, 1874 and 1875 are specially worthy of observation. Expressed in round numbers they are all represented by the figure I; but the exact figures are ${ }^{\circ} 49$, 0.74 , and 0.56 . To these low levels did the deaths by small pox fall after the epidemic of 1871. The epidemic itself is not more extreme on the one hand than the figures of the years which follow are on the other. The storm of that year, overleaping all barriers, was speedily followed by a calm as strange as the tempest itself. That atmospheric condition, whatever it may be, to which our epidemics are due, was so favourable to attacks of small pox that the barrier of vaccination, though effective in ordinary years, proved insufficient in this; the more and the less susceptible were alike seized, and the population swept clear for a time of almost all possible victims. Then vaccination, a protective in ordinary seasons, resumed its sway, and almost brought about the cessation of the small pox. I can imagine no better explanation than this; but whatever the efficacy of vaccination, certain it is that this nineteenth century in which it has been increasingly at work, and the last forty years, in which it has worked side by side with several sanitary reforms and improvements, have witnessed numerical phenomena which no sanitary reform can explain, and which vaccination alone appears competent to account for.

I shall now endeavour to present in a series of short propositions the conclusions which the figures of this paper appear to justify.

1. That our records of deaths by small pox in the metropolis reach back, with slight interruptions, two hundred and fifty years, together with similar returns of deaths by measles, and by all causes.

2. That if we use the deaths by all causes, year by year, as a standard of comparison by which to measure the deaths by small pox, and by other special maladies, we obtain ratios from which we can draw instructive inferences important in their bearing on such questions of practical importance as inoculation and vaccination.

3. That if we assume, in the case of small pox, 1oo deaths in $\mathrm{r}, 000$ from all causes to be an epidemic, and so name it, we find such epidemics to have been of frequent occurrence in the seventeenth and eighteenth centuries, and especially in the last half of the eighteenth, but absent in the nineteenth; and if we adopt a lower figure as the sign of an epidemic, we still have more epidemics in the two earlier centuries than in the present century. 
4. That the eighteenth century far surpasses both the seven. teenth and the nineteenth in the number, frequency, and magnitude of its epidemics; that it contributes more largely than they do to the sum of the deaths from all causes; and that it stands alone in presenting to us epidemics of more than one year's continuance.

5 . That the measles, on the contrary, if we take the ratio of 20 deaths per I,000 as the standard of an epidemic, shows a progressive and very oonsiderable increase from the seventeenth to the eighteenth, and from the eighteenth to the nineteenth century.

6. That whooping cough also, taking 25 deaths per 1,000 as the epidemic standard, shows an increased ratio of deaths in the nineteenth as compared with the eighteenth century.

7. That though the eighteenth century, and especially the last part of it, was remarkable for the number, frequency, and severity of its epidemics, and though it is probable that inoculation contributed to produce that result, it did nevertheless effect some saving of life by greatly mitigating the disease in most of those on whom it was brought to bear, thus somewhat more than counteracting the mischief it did by spreading the disease among those to whom it was not applied.

8. That any discrepancies which may seem to exist in the foregoing statement (No. 7) are reconciled when we take into acoount the fact that the lowest figures fell while the highest rose.

9. That a certain presumption in favour of vaccination as a preventive of small pox is afforded by the entire absence in the present century of epidemics of small pox, when so per cent. of the deaths from all causes is taken as the measure of an epidemic.

10. That this presumption is strengthened by the fact that small pox, up to the very close of the eighteenth century, had undergone no considerable abatement; also by the fact that the lowest returns of deaths by small pox are to be found in the nineteenth century as well as the longest interval between the only two epidemics whieh approach the standard of 10 per cent.

11. That the fall from the highest to the lowest ratio of deaths by small pox in the nineteenth century is greatly in excess of the fall from the highest to the lowest figure of the deaths by small pox in the eighteenth century.

12. That when we compare the eighteenth with the nineteenth century in the case of measles and whooping oough, we discover an opposite oondition of things-an increase of numbers instead of a decrease.

13. That there was a progressive lowering of the mortality from small pox in the early part of the nineteenth century prior to the introduction of sanitary reforms and improvements.

14. That this progressive decrease of mortality from small pox 
continued during the later years of this century after the introduction of these sanitary reforms and improrements.

15. That when we substitute for the ratio of deaths to deaths the ratio of deaths by small pox to the number of persons living, we change the figures without altering the results.

16. That when we make use of this ratio of deaths to the living, we find the deaths by small pox in roo, 000 living persons to fall from a maximum of 89 to a minimum of $\mathbf{s}$, a decrease quite unexampled in the case of other epidemics.

17. That the epidemics measles, scarlet fever and diphtheria whooping eough, fever and diarrhœea all undergo a decrease in the last forty years of this century, but that the decrease is only a small fraction of that which oceurred in the case of small pox ; their highest figure not amounting to a tenth part of the decrease of small pox.

18. That if we assume, as we are certainly justified in doing, that an equal improvement has been wrought by sanitary measures in all epidemic maladies, small pox included, we must needs attribute the remarkable excess of improvement in small pox to some cause or causes other than sanitary reforms, and that there is only one cause to which it is reasonable to attribute this excess, namely vaccination.

19. That there is nothing in the numerical surroundings of the great epidemic of the year 1871 (less severe, be it well understood, than the epidemics of the past centuries) which ought to shake our confidence in the preventive efficacy of vaccination; for the years which preceded, and still more those that followed it, show by the smallness of the figures to what a low degree of mortality some cause or causes could reduce this formidable malady, small pox.

20. That, taking a careful and compnehensive view of all the facts that bear upon this question, it is allowable to conjecture that while raccination does not act as a sufficient protection in epidemic years, it does effectually guard against attacks of small pox in all other years, and that where it does not protect it mitigates.

\section{SUPPLEMENT.}

I stated at the beginning of this paper that I was compelled to hold in reserve the figures and calculations for small pox and measles relating to England and Wales with which I had provided myself. I might have used these as the materials of a distinct communication to the Statistical Society; but, on consideration, I have preferred to treat them as a supplement to the present paper.

The figures are those of the twenty-eight years 1852 to 1879 inclusive. They are taken from the Forty-second Annual Report 
of the Registrar-General, p. Ixxii. This table at a first glance reveals the striking difference which exists between the rate of mortality prevailing in a large city, such as our metropolis, and an extensive tract of country such as England is. The easy communication between the several parts of a city and the comparatively difficult communication between one district and another of a kingdom, goes far to explain the different proportionate number of seizures; while the denser population explains the higher rate of mortality prevailing among those attacked. Roughly stated, the metropolis suffers more than a twofold loss by death, that is to say, twice the loss for England and Wales, London itself included, and much more than twice the loss of England and Wales if the metropolis were excluded. But this statement applies only to small pox. The difference in favour of England is much less in the case of measles. The lower death-rate for small pox, and the great difference between it and measles will appear more clearly if I compare the twenty-eight years for England with the figures for London during the same years.

TABLE XVIII.--England and London compared (One Hundred Thousand Deaths from all Causes).

\begin{tabular}{|c|c|c|c|c|}
\hline \multirow{2}{*}{ Years. } & \multicolumn{2}{|c|}{ Ratios of Small Pox. } & \multicolumn{2}{|c|}{ Ratios of Measles. } \\
\hline & London. & England. & London. & England. \\
\hline 1852 & $2, \mathrm{I} 2 \mathrm{I}$ & 1,798 & 1,088 & 1,435 \\
\hline 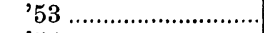 & $35^{\mathrm{I}}$ & 748 & I, 628 & 1,162 \\
\hline '54 & $94 \mathrm{I}$ & 641 & I,9 I I & 2,118 \\
\hline 55 & 1,677 & 593 & 1,417 & 1,727 \\
\hline '56 ………………........ & 927 & 583 & 2,582 & 1,824 \\
\hline '57 „........................... & 263 & 937 & 2,268 & 1,419 \\
\hline '58 & 377 & 1,436 & 3,696 & 1,950 \\
\hline 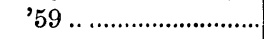 & $\mathrm{I}, 855$ & 873 & 2,150 & 2,166 \\
\hline 1860 & $\mathrm{I}, 44 \mathrm{I}$ & 650 & 3,354 & 2,260 \\
\hline 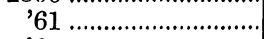 & 332 & 303 & 1,627 & 2,081 \\
\hline '62 & 543 & 373 & 3,464 & 2,244 \\
\hline '63 ................................... & 2,808 & 1,258 & 2,299 & 2,395 \\
\hline '64 ..., & 699 & 1,550 & 3,563 & 1,679 \\
\hline '65 & 870 & 1,306 & $\mathrm{r}, 753$ & 1,744 \\
\hline '66 & 1,728 & 604 & 2,759 & 2,184 \\
\hline 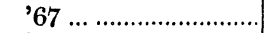 & 1,896 & 533 & $\mathrm{I}, 6 \mathrm{II}$ & 1,398 \\
\hline '68 & 809 & 427 & 2,659 & 2,419 \\
\hline 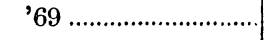 & 352 & 316 & 1,865 & 2,083 \\
\hline 1870 & $\mathrm{I}, 253$ & 508 & 1,866 & 1,463 \\
\hline 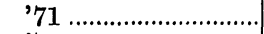 & 9,837 & 4,491 & 1,774 & 1,804 \\
\hline 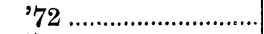 & 2,502 & 3,878 & 2,354 & 1,732 \\
\hline …………....... & I 49 & 479 & 2,847 & 1,503 \\
\hline 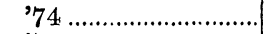 & 74 & 410 & 2,187 & 2,327 \\
\hline '75 ....... & 56 & 173 & 1,717 & 1,139 \\
\hline 76 & 947 & 472 & 2,214 & 1,953 \\
\hline '77 ……………........... & 3,293 & 854 & 3,082 & 1,807 \\
\hline '78 ………………...... & $I, 683$ & 343 & $\mathrm{I}, 78 \mathrm{I}$ & 1,438 \\
\hline '79 .................. & $53^{6}$ & 102 & 2,953 & 1,746 \\
\hline Sum of ratios......... & 40,320 & 26,639 & 64,469 & 51,200 \\
\hline
\end{tabular}


In commenting upon this table I will follow as nearly as I can the order already adopted in the case of the metropolis.

1. Of Epidemics of Small Pox, their Magnitude and Number.The scale of 10 per cent., which I took as a convenient measure of an epidemic for London, is not applicable to England; but if we may assume 35 and upwards as our epidemic standard, we should have only two epidemics in the twenty-eight years. These would occur in the year 1871 (the chief of the two years in which the deaths by small pox in London approached the ratio of so per cent.) and the following year 1872. It may be said, indeed, that, as in London we had two epidemics in the twenty-eight years approaching the old standard of 10 per cent., so in England we had one epidemic extending over two years, the number of deaths being less than half of those that marked the London epidemic of 1871.

2. The Maxima and Minima.-Whereas the maxima and minima for London in the twenty-eight years are 9,837 and 56 , those for all England are 4,491 and s02.

3. Frequency of Epidemics.-Though we had in England in the twenty-eight years but one epidemic of two years' duration, there are five other years in which the ratios are represented by four figures, and these high figures are separated by intervals of five, four, and five years, while the epidemie of 1871-72 is followed by seven years of comparatively low mortality.

4. Epidemics of Measles.-If we continue to take 20 deaths in the 1,000 as a measure of an epidemic, we have ten epidemics in the twenty-eight years. But it is noticeable that between measles in London and measles in England, there is much less difference than between small pox in London and small pox in England. Measles shows a fall of less than I in 5, while small pox in England is less than in London as 26 is less than 40. Small pox in England, therefore, when compared with small pox in London as a standard, shows a much lower rate of mortality than measles does.

5. In order to discuss the bearing of the facts relating to small pox in England on vaccination (for inoculation has no place in this inquiry), it will be necessary to arrange the figures in four equal periods of seven years. This is done in the table which follows; the facts for measles being added, and London included :- 
TABle XIX.-Small Pox in England in Periods of Seven Years.

\begin{tabular}{|c|c|c|c|c|c|c|c|c|c|c|c|c|}
\hline \multirow{3}{*}{ Years. } & \multicolumn{6}{|c|}{ Small Pox. } & \multicolumn{6}{|c|}{ Measles. } \\
\hline & \multicolumn{3}{|c|}{ London. } & \multicolumn{3}{|c|}{ England. } & \multicolumn{3}{|c|}{ London. } & \multicolumn{3}{|c|}{ England. } \\
\hline & $\begin{array}{l}\text { Max- } \\
\text { ima. }\end{array}$ & $\begin{array}{l}\text { Min- } \\
\text { Ima. }\end{array}$ & $\begin{array}{l}\text { Aver- } \\
\text { age. }\end{array}$ & $\begin{array}{l}\text { Max- } \\
\text { ima. }\end{array}$ & $\begin{array}{l}\text { Min. } \\
\text { ima. }\end{array}$ & $\begin{array}{l}\text { Aver- } \\
\text { age. }\end{array}$ & $\begin{array}{l}\text { Max- } \\
\text { ima. }\end{array}$ & $\begin{array}{l}\text { Min- } \\
\text { ima. }\end{array}$ & $\begin{array}{l}\text { Aver- } \\
\text { age. }\end{array}$ & $\begin{array}{l}\text { Max- } \\
\text { ima. }\end{array}$ & $\begin{array}{l}\text { Min- } \\
\text { ima. }\end{array}$ & $\begin{array}{l}\text { Aver- } \\
\text { age. }\end{array}$ \\
\hline $1852-58$ & $2,12, I$ & 263 & $95 \mathrm{I}$ & 1,798 & 593 & 962 & 3,695 & 1,088 & 2,084 & $2, \mathrm{I}$ I 8 & 1,162 & $\mathrm{I}, 662$ \\
\hline '59-65 & $\begin{array}{r}x \\
2,808\end{array}$ & $\begin{array}{r}\times \\
332\end{array}$ & $\begin{array}{r}x \\
1,22,1\end{array}$ & $\mathrm{I}, 55^{\circ}$ & 303 & 902 & $\frac{\times}{3,563}$ & $\begin{array}{r}\times \\
1,625\end{array}$ & $\begin{array}{r}x \\
2,601\end{array}$ & $\begin{array}{r}\times \\
2,395\end{array}$ & $\begin{array}{r}x \\
1,744\end{array}$ & $\underset{2,081}{x}$ \\
\hline & & $x$ & & $x$ & $x$ & & & & & & & \\
\hline '66-72 & 9,837 & 352 & 2,625 & 4,49 I & 316 & 1,539 & 2,759 & 1,611 & 2,024 & 2,419 & 1,398 & 1,869 \\
\hline $73-79$ & 3,293 & 56 & 2,397 & 872 & 102 & 405 & 3,082 & $1,717^{\times}$ & $\begin{array}{r}x \\
2,397\end{array}$ & 2,327 & 1,139 & 1,702 \\
\hline
\end{tabular}

It will be seen from this table that all the figures for Englandthe maxima, the minima, and the averages-show a greatly diminishing death-rate by small pox, and are consistent with the alleged efficiency of vaccination as a preventive. The maximum mortality falls in the twenty-eight years from 1,798 in the 100,000 deaths to 872 , or less than one-half, the minimum from nearly 600 to little more than 100, or a sixth, and the average from 962 to 405 , or considerably more than a half. The figures would have shown a progressive decrease but for the remarkable increase of small pox mortality which characterised the seven years from 1866 to 1872 inclusive, and attained its climax in the epidemic of 1871. There is nothing therefore in these figures to militate against the protective power of vaccination, and much in its support.

But this group of annual returns for London does not yield the same support to the theory of the protective power of vaccination. The maxima show a progressive increase, even when the figures for the epidemic of 1871 are set aside, and the same is true of the averages; but the curiously low figure of $5^{6}$ per 100,000 deaths still figures among the minima of the last seven years. Here, however, it is necessary to remark, that if the figures thus grouped do not lend support to vaccination, neither do they confirm the theory of progressive sanitary improvement.

On the other hand, the figures for measles show for this same period of twenty-eight years, but a slightly decreased death-rate for England when measured by the minima, but an increased rate when tested by the maxima and the averages; while for London the minima and the averages exhibit a considerable increase, but the maxima a progressive decrease. 


\section{A P P E N D IX.}

TABLE I.-Deaths from Small Pox and Measles, and from all Causes, in London, 1629 to 1879.

\begin{tabular}{|c|c|c|c|c|c|}
\hline \multirow{3}{*}{ Years. } & \multicolumn{3}{|c|}{ Deaths by } & \multicolumn{2}{|c|}{ Ratio of Deaths by } \\
\hline & \multirow{2}{*}{$\begin{array}{c}\text { F'lox } \\
\text { and Small Pox. }\end{array}$} & \multirow{2}{*}{ Measles. } & \multirow{2}{*}{ All Causes. } & $\begin{array}{c}\text { Flox } \\
\text { and Small Pox }\end{array}$ & Measies \\
\hline & & & & \multicolumn{2}{|c|}{ to $\mathrm{r}, \infty \infty$ Deaths from all Causes } \\
\hline $1629 \ldots \ldots$ & 72 & 42 & $8,8 \mathrm{I} 4$ & $8 \cdot 17$ & 4.47 \\
\hline $30 \ldots . . . .$. & 40 & 2 & 10,471 & $3 \cdot 82$ & 0.19 \\
\hline '31 ......... & $5^{8}$ & 3 & $8,45^{8}$ & $6 \cdot 85$ & 0.35 \\
\hline '32 .......... & 531 & 80 & 9,539 & $55 \cdot 66$ & $8 \cdot 38$ \\
\hline '33 .......... & 72 & 21 & 8,427 & $8 \cdot 54$ & $2: 49$ \\
\hline '34 .......... & $\mathbf{r}, 354$ & 33 & 10,865 & $124 \cdot 62$ & $3^{\circ} \circ 3$ \\
\hline '35 .......... & 293 & 27 & 10,641 & $27 \cdot 53$ & $2 \cdot 53$ \\
\hline '36 ......... & 127 & 12 & 23,382 & $5 \cdot 43$ & 0.51 \\
\hline $1647 \ldots \ldots$. & I 39 & $\mathbf{5}$ & $\mathrm{I}_{3}, 784$ & $10 \cdot 08$ & 0.36 \\
\hline '48 ......... & 400 & 92 & 9,896 & 40.42 & $93^{\circ} \circ 0$ \\
\hline ' $49 \ldots \ldots . . . .$. & $\mathrm{I}, \mathrm{I} 90$ & 3 & 10,532 & $112 \cdot 29$ & 0.28 \\
\hline '50 ......... & 184 & 33 & $8,68 \mathrm{I}$ & $21 \cdot 19$ & $3 \cdot 80$ \\
\hline '51 ......... & 525 & 33 & 10,773 & $48 \cdot 73$ & $3^{\circ} \circ 6$ \\
\hline '52 ......... & 1,279 & 62 & $12,54 \mathrm{I}$ & $101 \cdot 98$ & 4.94 \\
\hline '53 ......... & 139 & 8 & 9,082 & $15 \cdot 30$ & 0.88 \\
\hline '54 .......... & 812 & 52 & 13,126 & $61 \cdot 86$ & 3.96 \\
\hline '55 .......... & 1,294 & 11 & 11,409 & $113 \cdot 42$ & 0.96 \\
\hline '56 ......... & 823 & 153 & I 3,752 & $59 \cdot 85$ & II'12 \\
\hline '57 ......... & 835 & 15 & 12,434 & $67 \cdot 15$ & $1 \cdot 20$ \\
\hline '58 .......... & 409 & 80 & I 4,993 & $27 \cdot 27$ & $5^{\circ} 33$ \\
\hline '59 ........ & 1,523 & 6 & 14,756 & $103 \cdot 21$ & 0.40 \\
\hline '60 ........ & 354 & 74 & I 5, I 18 & $23 \cdot 41$ & $4 \cdot 89$ \\
\hline '61 ........ & 1,246 & 188 & I 9,77 I & $63 \cdot 02$ & 9.50 \\
\hline '62 .......... & 768 & 20 & I 6,554 & $46 \cdot 39$ & $1 \cdot 20$ \\
\hline '63 ......... & 4II & 42 & I 5,356 & $26 \cdot 76$ & $2 \cdot 73$ \\
\hline '64 .......... & 1,233 & 311 & 18,297 & $67 \cdot 38$ & 16.99 \\
\hline '65 ............. & 655 & 7 & 97,306 & $6 \cdot 73$ & 0.07 \\
\hline '66 .......... & 38 & 3 & I $2,73^{8}$ & $2 \cdot 98$ & 0.23 \\
\hline '67 ......... & I, I 96 & 83 & I 5,842 & $75 \cdot 49$ & $5^{\circ 23}$ \\
\hline '68 ......... & 1,987 & 200 & 17,278 & $115 \cdot 00$ & $11 \cdot 57$ \\
\hline '69 ......... & $95^{x}$ & 15 & 19,432 & $48 \cdot 93$ & 0.77 \\
\hline '70 ......... & 1,465 & 295 & 20,198 & $72 \cdot 53$ & $14^{\circ} 60$ \\
\hline '71 ......... & 696 & 7 & I 5,729 & $44 \cdot 24$ & 0.44 \\
\hline '72 .......... & I, I I 6 & 118 & 18,230 & $61 \cdot 21$ & $6 \cdot 47$ \\
\hline '73 ............ & 853 & 15 & I 7,504 & $48 \cdot 73$ & 0.85 \\
\hline '74 ......... & 2,507 & 795 & 21,201 & $118 \cdot 24$ & 3749 \\
\hline '75 .......... & 997 & 1 & I 7,244 & $57 \cdot 81$ & 0.05 \\
\hline '76 ......... & 359 & 83 & I 8,732 & $19 \cdot 16$ & $4 \cdot 43$ \\
\hline '77 ............ & 1,678 & 87 & 19,067 & $88 \cdot 00$ & 456 \\
\hline 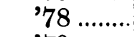 & 1,798 & 93 & 20,678 & 86.95 & 449 \\
\hline '79 ........... & 1,967 & 117 & 21,730 & 90.52 & $5 \cdot 38$ \\
\hline '80 .............. & 689 & 49 & 21,053 & $32 \cdot 72$ & $2 \cdot 32$ \\
\hline '81 ........... & 2,982 & 121 & $23,97 \mathrm{I}$ & $124 \cdot 40$ & $5^{\circ} 04$ \\
\hline '82 ........... & $1,4 \subset 8$ & 50 & $20,69 \mathrm{I}$ & 68.04 & $2.4 \mathrm{I}$ \\
\hline '83 ........ & 2,096 & 39 & 20,587 & $101 \cdot 81$ & $I \cdot 89$ \\
\hline ' $84 \ldots . . . .$. & 1,560 & 6 & 23,202 & $67 \cdot 23$ & 0.25 \\
\hline '85 .......... & 2,496 & 197 & 23,222 & $107 \cdot 48$ & $8 \cdot 48$ \\
\hline '86 .......... & 1,062 & 25 & 22,609 & $46 \cdot 97$ & 1.70 \\
\hline
\end{tabular}


TABLE I.-Deaths from Small Pox, Measles, and all Causes-Contd.

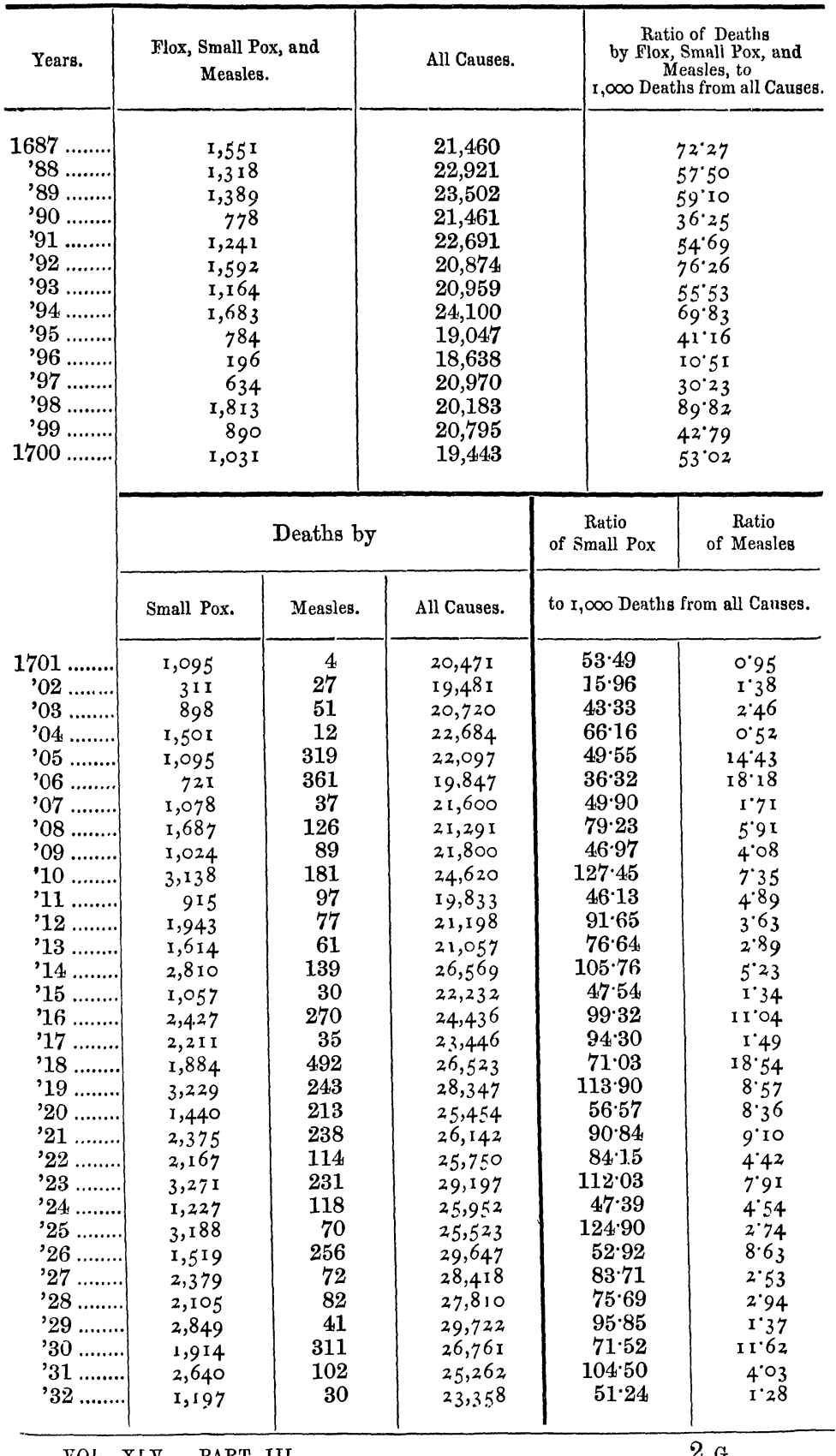

VOL. XLV. PART III. 
TABLE I.-Deaths from Small Pox, Measles, and all Causes-Contd.

\begin{tabular}{|c|c|c|c|c|c|}
\hline \multirow{2}{*}{ Years. } & \multicolumn{3}{|c|}{ Deaths by } & Ratio & Ratio \\
\hline & Small Pox. & Measles. & All Causes. & \multicolumn{2}{|c|}{ to $I, \infty \infty$ Deaths from all Causes. } \\
\hline $1733 \ldots \ldots .$. & 1,370 & 605 & 29,233 & $46 \cdot 86$ & 20.69 \\
\hline $34 \ldots . . . .$. & 2,688 & 20 & 26,062 & $103 \cdot 13$ & 0.76 \\
\hline '35 .......... & $\mathbf{I}, 594$ & 10 & 23,538 & $67 \cdot 72$ & 0.42 \\
\hline '36 ......... & 3,014 & 169 & 27,581 & $109 \cdot 27$ & $6 \cdot 12$ \\
\hline '37 .......... & 2,084 & 127 & 27,823 & $74: 90$ & $4 \cdot 56$ \\
\hline '38 .......... & 1,590 & 216 & 25,825 & $61 \cdot 56$ & $8 \cdot 36$ \\
\hline '39 .............. & 1,690 & 326 & 25,432 & $66 \cdot 45$ & $12: 81$ \\
\hline '40 .......... & 2,725 & 46 & 30,8 I I & $88 \cdot 44$ & $\mathrm{I} \cdot 48$ \\
\hline '41. & 1,977 & 42 & 32,169 & $61 \cdot 45$ & $1 \cdot 30$ \\
\hline ' $42 \ldots \ldots$. & 1,429 & 981 & 27,483 & 51.99 & $35^{\circ} 69$ \\
\hline '43 ......... & 2,029 & 17 & 25,200 & 80.51 & 0.67 \\
\hline '44. & 1,633 & 5 & 20,606 & $79 \cdot 24$ & 0.24 \\
\hline '45 .......... & 1,206 & 14 & 21,296 & $56 \cdot 63$ & 0.65 \\
\hline '46 .................. & 3,236 & 250 & 28,157 & $114: 92$ & $8 \cdot 87$ \\
\hline '47 ............ & 1,380 & 81 & 25,494 & $54: 13$ & 3.17 \\
\hline $48 \ldots \ldots \ldots$ & 1,789 & 10 & 23,869 & $74: 95$ & 0.41 \\
\hline 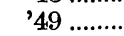 & 2,625 & 106 & 25,516 & $102 \cdot 87$ & $4 \div 5$ \\
\hline '50 .......... & 1,229 & 321 & 23,727 & $52 \cdot 64$ & 1352 \\
\hline '51 ......... & 998 & 21 & 21,028 & $47 \cdot 46$ & 0.99 \\
\hline '52 ........ & 3,538 & 111 & 20,485 & $172 \cdot 71$ & $5.4 I$ \\
\hline '53 ........ & 774 & 253 & 19,276 & $40 \cdot 15$ & 13.12 \\
\hline '54 .......... & 2,359 & 12 & 22,696 & 103.93 & 0.52 \\
\hline '55 ........... & 1,988 & 423 & 21,917 & 90.70 & 19.30 \\
\hline '56 ........ & i, 608 & 156 & 20,872 & $77 \cdot 04$ & 7.42 \\
\hline '57 .................. & $3, \sqrt{9} 6$ & 24 & 21,313 & $154: 64$ & $I \cdot I 2$ \\
\hline '58 .......... & 1,273 & 696 & 17,576 & $72 \cdot 42$ & $39^{\circ} 59$ \\
\hline '59 ......... & 2,596 & 316 & 19,604 & $132 \cdot 42$ & 16.12 \\
\hline '60 ......... & 2,187 & 175 & I 9,830 & $110 \cdot 28$ & $8 \cdot 82$ \\
\hline '61 ......... & $x, 525$ & 394 & 21,063 & $72 \cdot 40$ & 18.70 \\
\hline 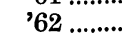 & 2,743 & 122 & 26,326 & $104 \cdot 19$ & $4 \cdot 63$ \\
\hline 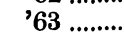 & 3,582 & 610 & 26,148 & 136.98 & 23.32 \\
\hline${ }^{\prime} 64 \ldots \ldots \ldots$ & 2,382 & 65 & 23,202 & $102 \cdot 66$ & $2 \cdot 80$ \\
\hline${ }^{\prime} 65 \ldots . . . .$. & 2,498 & 54 & 23,230 & 107.53 & $2 \cdot 32$ \\
\hline '66 ......... & 2,334 & 482 & 23,9 I I & $97 \cdot 61$ & $20^{\circ} 15$ \\
\hline '67 ......... & 2,188 & 80 & 22,6 I 2 & 96.76 & 3.53 \\
\hline '68 ......... & 3,028 & 409 & 23,639 & $128 \cdot 09$ & 17.30 \\
\hline 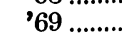 & $\mathrm{I}, 968$ & 90 & 21,847 & 90.08 & $4 \cdot 11$ \\
\hline .................. & 1,986 & 325 & 22,434 & $88 \cdot 52$ & $\begin{array}{r}4.48 \\
1448\end{array}$ \\
\hline ' $71 \ldots . . . . . . .$. & 1,660 & 115 & 21,780 & $76 \cdot 21$ & $52 \cdot 80$ \\
\hline $772 \ldots . . . .$. & 3,992 & 211 & 26,053 & $15 \cdot 32$ & 8.09 \\
\hline 73 ............... & 1,039 & 199 & 21,656 & $47 \cdot 97$ & 9.18 \\
\hline $174 \ldots . . . .$. & 2,479 & 121 & 20,884 & $118 \cdot 70$ & 579 \\
\hline '75 ......... & 2,669 & 283 & $20,5 \times 4$ & $130 \cdot 10$ & 13.79 \\
\hline ........ & 1,728 & 153 & 19,048 & $90 \cdot 71$ & 8.03 \\
\hline י......... & 2,567 & 145 & 23,334 & 110.01 & $6 \cdot 21$ \\
\hline י............. & $\mathrm{I}, 425$ & 388 & 20,399 & 69.85 & 19.02 \\
\hline י............. & 2,493 & 99 & 20,420 & $122 \cdot 08$ & $4 \cdot 84$ \\
\hline '80 ......... & $87 \mathrm{t}$ & 272 & 20,517 & $42 \cdot 45$ & 13.25 \\
\hline '81 ......... & 3,500 & 201 & 20,709 & $169 \cdot 00$ & 9.70 \\
\hline '82 .......... & $6_{3} 6$ & 170 & 17,918 & $35 \cdot 49$ & $9 \cdot 48$ \\
\hline '83 ......... & 1,550 & 185 & 19,029 & $81 \cdot 45$ & 9.72 \\
\hline ' $84 . . . . . . .$. & 1,759 & 29 & 17,828 & $98 \cdot 66$ & $1 \cdot 62$ \\
\hline
\end{tabular}


TABle I.-Deaths from Small Pox, Measles, and all Causes-Contd.

\begin{tabular}{|c|c|c|c|c|c|}
\hline \multirow{2}{*}{ Years. } & \multicolumn{3}{|c|}{ Deaths by } & $\begin{array}{c}\text { Ratio } \\
\text { of Small Pox }\end{array}$ & $\begin{array}{c}\text { Ratio } \\
\text { of Measles }\end{array}$ \\
\hline & Small Pox. & Measles. & All Causes. & \multicolumn{2}{|c|}{ to $I, \infty \infty$ Deaths from all Causes. } \\
\hline 1785 & I,999 & 20 & 18,919 & $105 \cdot 66$ & I.O5 \\
\hline '86 ......... & 1,210 & 793 & 20,454 & $59 \cdot 15$ & 38.76 \\
\hline '87 ......... & 2,418 & 84 & 19,349 & $124 \cdot 96$ & $4 \cdot 34$ \\
\hline '88 & 1,101 & 55 & I 9,697 & $55 \cdot 89$ & $2 \cdot 79$ \\
\hline '89 .......... & 2,077 & 534 & 20,749 & $100 \cdot 10$ & 25.73 \\
\hline$' 90 \ldots . . . . .$. & $\mathrm{x}, 6 \mathrm{xy}$ & 119 & 18,038 & $89 \cdot 64$ & 6.59 \\
\hline '91 ............... & 1,747 & 156 & 18,760 & $93 \cdot 12$ & $8 \cdot 3 \mathrm{I}$ \\
\hline '92 & 1,568 & 450 & 20,2 I 3 & $77 \cdot 57$ & $22 \cdot 26$ \\
\hline '93 & 2,382 & 248 & 21,749 & 109.52 & $\mathrm{II}_{4} 40$ \\
\hline '94 .......... & $1,9 \times 3$ & 172 & $19,24 \mathrm{I}$ & $99 \cdot 42$ & 8.93 \\
\hline '95 .......... & 1,040 & 328 & 21,179 & $49 \cdot 10$ & 1548 \\
\hline '96 ........... & 3,548 & 307 & 19,288 & $183 \cdot 94$ & $\times 5^{\circ} 9 x$ \\
\hline '97 ............. & 522 & 222 & I 7,014 & 30.68 & $13^{\circ} 04$ \\
\hline '98 ............. & 2,337 & 196 & I 8, I 55 & 128.72 & 1079 \\
\hline '99 .......... & 1, I I I & 223 & 18,134 & $61 \cdot 26$ & 12.29 \\
\hline $1800 \ldots \ldots$. & 2,409 & 395 & 23,068 & $104: 43$ & $17 \cdot 12$ \\
\hline '01 ......... & $\mathrm{I}, 4 \kappa_{1}$ & 136 & I 9,374 & $75 \cdot 41$ & 7.02 \\
\hline '02 ........ & 1,579 & 559 & 19,379 & $81 \cdot 99$ & $28 \cdot 48$ \\
\hline '03 ............ & 1,202 & 438 & I 9,582 & $61 \cdot 38$ & $22 \cdot 36$ \\
\hline 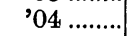 & 622 & 619 & 17,034 & 36.50 & $36 \cdot 33$ \\
\hline $05 \ldots . . . .$. & 1,685 & 523 & $\mathrm{I} 7,565$ & 95.92 & 29.77 \\
\hline '06 ............. & 1,158 & 530 & I 7,938 & $64: 55$ & 29.54 \\
\hline '07 .......... & $x, 297$ & 452 & I 8,334 & 70.74 & $24^{\circ} 5^{6}$ \\
\hline '08 .......... & 1,169 & 1,386 & I 9,954 & $58 \cdot 58$ & $69 \cdot 45$ \\
\hline '09 ......... & $\mathrm{I}, \mathrm{I} 63$ & 106 & I 6,680 & 69.72 & 6.35 \\
\hline${ }^{\prime} 10 \ldots . . . .$. & $\mathbf{1}, 198$ & 1,031 & 19,893 & $60 \cdot 22$ & $5 I \cdot 82$ \\
\hline$' 11 \ldots . . .$. & $75 \mathrm{I}$ & 235 & 17,043 & $44: 06$ & 13.78 \\
\hline$' 12 \ldots \ldots . .$. & 1,287 & 427 & I 8,295 & $70 \cdot 34$ & 23.33 \\
\hline '13 .......... & 898 & 550 & 17,322 & 51.89 & $31 \cdot 75$ \\
\hline 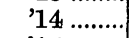 & 638 & 817 & 19,283 & 33.08 & $42 \cdot 36$ \\
\hline$' 15 \ldots \ldots . .$. & 725 & 711 & 19,560 & $37 \cdot 06$ & $36 \cdot 34$ \\
\hline '16 .......... & 653 & 1,106 & 20,316 & $32 \cdot 14$ & 54.43 \\
\hline '17 ........ & $I, 051$ & 725 & I 9,968 & $52 \cdot 63$ & $36 \cdot 30$ \\
\hline '18 ............ & 421 & 728 & 19,705 & $21 \cdot 36$ & $36 \cdot 94$ \\
\hline '19 ......... & 712 & 695 & 19,228 & 37.02 & $36 \cdot 14$ \\
\hline 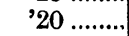 & 792 & 720 & x 9,348 & 40.93 & 37.21 \\
\hline '21 ........ & 508 & 547 & $18,45^{1}$ & $27 \cdot 53$ & $29^{\circ} 64$ \\
\hline '22 .......... & 604 & 712 & I 8,865 & $32 \cdot 01$ & 37.74 \\
\hline '23 ......... & 774 & 573 & 20,587 & $37 \cdot 59$ & 27.83 \\
\hline '24 ......... & 725 & 966 & 20,237 & $35 \cdot 82$ & 17.73 \\
\hline '25 .......... & 1,299 & 743 & 21,026 & $61 \cdot 78$ & $35^{\circ} 33$ \\
\hline '26 ........ & 503 & 774 & 20,758 & $24: 23$ & $37 \cdot 28$ \\
\hline $27 \ldots \ldots . .$. & 616 & 525 & 22,292 & $27 \cdot 63$ & 23.55 \\
\hline '28 ......... & 598 & 736 & 21,709 & $27 \cdot 54$ & 33.90 \\
\hline '29 ........ & 736 & 578 & $23,5^{24}$ & $31 \cdot 28$ & 24.57 \\
\hline '30 ............ & 627 & 479 & 21,645 & $28 \cdot 97$ & $22 \div 12$ \\
\hline '31 .......... & 563 & 750 & 25,337 & $22 \cdot 22$ & $29 \cdot 60$ \\
\hline $1841 \ldots . . . .$. & 1,053 & 973 & 45,507 & $23 \cdot 11$ & $21 \cdot 38$ \\
\hline 42 & 360 & 1,293 & 45,400 & $7 \cdot 92$ & $28 \cdot 48$ \\
\hline '43 ......... & 438 & 1,442 & 48,718 & 8.99 & $29^{\circ} 60$ \\
\hline ' $444 \ldots . . . . .$. & $\mathrm{J}, 804$ & 1,182 & $5 \mathrm{I}, \mathrm{I} 10$ & $35 \cdot 29$ & $23 \cdot 12$ \\
\hline
\end{tabular}


TABLE I.-Deaths from Small Pox, Measles, and all Causes-Contd.

\begin{tabular}{|c|c|c|c|c|c|}
\hline \multirow{2}{*}{ Years. } & \multicolumn{3}{|c|}{ Deaths by } & $\begin{array}{c}\text { Ratio } \\
\text { of Small Pox }\end{array}$ & $\begin{array}{c}\text { Ratio } \\
\text { of Measles }\end{array}$ \\
\hline & Small Pox. & Measles. & All Causes. & \multicolumn{2}{|c|}{ to $1, \infty 0$ Deaths from all Causes. } \\
\hline $1845 \ldots \ldots . .$. & 909 & 2,318 & 48,318 & $18 \cdot 81$ & 47.97 \\
\hline '46 ......... & 257 & 747 & $49,45^{\circ}$ & $5 \cdot 10$ & T 5.10 \\
\hline $47 \ldots \ldots . .$. & 955 & 1,778 & 59, I 3 I & $16 \cdot 15$ & 30.06 \\
\hline $48 \ldots . . . .$. & $\mathrm{I}, 620$ & 1,144 & 57,771 & $28 \cdot 04$ & 19.80 \\
\hline $49 \ldots \ldots$. & $5^{2} \mathrm{I}$ & 1,154 & 68,755 & $7 \cdot 57$ & $16 \cdot 78$ \\
\hline '50 ......... & 499 & 980 & 48,950 & $10 \cdot 19$ & 20.02 \\
\hline '51 ........ & 1,062 & 1,297 & 55,488 & $19 \cdot 13$ & 23.37 \\
\hline '52 ........ & $\mathrm{r}, \mathrm{I} 59$ & 595 & 54,638 & $21 \cdot 21$ & 10.88 \\
\hline '53 ......... & 2,11 & 978 & 60,069 & $3 \cdot 51$ & $16 \cdot 28$ \\
\hline '54 ......... & 694 & 1,409 & 73,697 & $9 \cdot 41$ & I9. I I \\
\hline '55 .......... & 1,039 & 878 & 61,942 & $16 \cdot 77$ & $14 \times 7$ \\
\hline '56 ......... & $53 \mathrm{I}$ & 1,479 & 57,274 & $9 \cdot 27$ & $25^{\circ} 82$ \\
\hline '57 .......... & 156 & 1,341 & 59,103 & $2 \cdot 63$ & $22 \cdot 68$ \\
\hline '58 ......... & 242 & 2,369 & 64,093 & $3 \cdot 77$ & 36.96 \\
\hline '59 ......... & $\mathrm{I}, \mathrm{I} 5^{8}$ & 1,330 & $6 \mathrm{I}, 860$ & 18.55 & $21 \cdot 50$ \\
\hline '60 ......... & 898 & 2,090 & 62,309 & $14 \cdot 41$ & $33 \cdot 54$ \\
\hline '61 ........ & 217 & 1,062 & $65,25 \mathrm{I}$ & $3 \cdot 32$ & 16.27 \\
\hline ' 62 ........... & 366 & 2,334 & 67,371 & $5 \cdot 43$ & 34.64 \\
\hline '63 ......... & $x, 996$ & 1,634 & 71,060 & $28 \cdot 08$ & 22.99 \\
\hline ' $64 \ldots . . . . .$. & 547 & 2,788 & 78,238 & 6.99 & 35.63 \\
\hline ' $65 \ldots \ldots . . .$. & 640 & 1,290 & $73,53 \mathbf{I}$ & $8 \cdot 70$ & 1753 \\
\hline '66 ........ & $\mathrm{I}, 39 \mathrm{I}$ & 2,220 & 80,453 & $17 \cdot 28$ & 2759 \\
\hline '67 ......... & $\mathrm{I}, 345$ & 1,143 & 70,924 & $18 \cdot 96$ & 16.11 \\
\hline '68 ......... & 597 & 1,962 & 73,798 & $8 \cdot 09$ & $26 \cdot 59$ \\
\hline '69 .......... & 275 & 1,456 & 78,082 & $3 \cdot 52$ & 18.65 \\
\hline '70 .......... & 973 & 1,449 & 77,634 & 12.53 & 18.66 \\
\hline '71 ......... & 7,912 & $1,4,27$ & 80,430 & $98 \cdot 37$ & 17.74 \\
\hline '72 ................. & $\mathrm{I}, 786$ & 1,680 & 71,355 & $25 \cdot 02$ & 23.54 \\
\hline '73 ......... & I I 3 & 2,149 & 75,459 & $1 \cdot 49$ & 28.47 \\
\hline '74 ......... & 57 & 1,680 & 76,813 & 0.74 & $21 \cdot 87$ \\
\hline $75 \ldots . . .$. & 46 & $1,4,08$ & 81,964 & 0.56 & $17 \cdot 17$ \\
\hline $76 \ldots . . . .$. & 736 & 1,720 & $77,67 \mathrm{I}$ & $9 \cdot 4.7$ & 22.14 \\
\hline '77 ......... & $2,55^{\mathrm{I}}$ & 2,387 & 77,449 & 32.93 & 30.82 \\
\hline 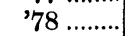 & 1,417 & 1,500 & 84,188 & $16 \cdot 83$ & 17.81 \\
\hline '79 ............ & $45^{\circ}$ & 2,475 & 83,805 & $5 \cdot 36$ & 29.53 \\
\hline '80 ............. & 475 & 1,501 & 81,128 & $5 \cdot 85$ & 18.50 \\
\hline '81 ......... & 2,371 & 2,533 & 81,071 & $29 \cdot 24$ & $3 I^{\circ} 25$ \\
\hline
\end{tabular}


TABLe II (APpendix).-Maxima and Minima at Different Periods.

\begin{tabular}{|c|c|c|}
\hline & Maxima. & Minima \\
\hline \multicolumn{3}{|l|}{ For Periods of Thirty Years- } \\
\hline $1647-76$ & 118 & 2.98 \\
\hline 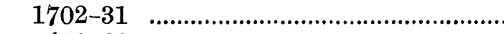 & 127 & 16.00 \\
\hline '32-61 & 173 & 40.15 \\
\hline '62 91 & 169 & $152^{2}$ \\
\hline 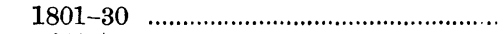 & 96 & $21 \cdot 36$ \\
\hline '41-70 & 35 & $2 \cdot 63$ \\
\hline \multicolumn{3}{|l|}{ For Periods of Forty Fears- } \\
\hline $1647-86$ & 124 & $2 \cdot 98$ \\
\hline $1702-41$ & 127 & $36^{\circ} 00$ \\
\hline '42-81 & 173 & 15.00 \\
\hline 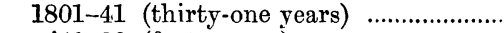 & 96 & $2 \mathrm{I} \cdot 36$ \\
\hline 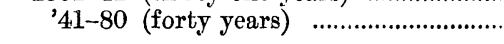 & 98 & 0.56 \\
\hline \multicolumn{3}{|l|}{ By Centuries- } \\
\hline Seventeenth century (forty-eight years) & 124 & $2^{\circ} 98$ \\
\hline Eighteenth " (one hundred ") & 183 & $15 \cdot 32$ \\
\hline " (eighty & 98 & $0^{\circ} 5^{6}$ \\
\hline
\end{tabular}

TABLE II*.-Small Pox and Measles in Engrand, 1852 to 1879 inclusive.

\begin{tabular}{|c|c|c|c|c|c|}
\hline Years. & $\begin{array}{c}1 \\
\text { All Causes of } \\
\text { Death. }\end{array}$ & $\begin{array}{c}2 \\
\text { Small Pox. }\end{array}$ & Ratio of 1 to 2. & $\begin{array}{c}3 \\
\text { Measles. }\end{array}$ & Ratio of 1 to 3 . \\
\hline 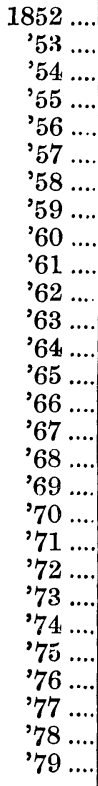 & $\begin{array}{l}407,135 \\
421,097 \\
437,905 \\
425,703 \\
390,506 \\
419,815 \\
449,656 \\
440,781 \\
422,721 \\
435,114 \\
436,566 \\
473,837 \\
495,531 \\
490,909 \\
500,689 \\
471,073 \\
480,622 \\
494,828 \\
515,329 \\
514,879 \\
492,265 \\
492,520 \\
526,632 \\
546,453 \\
510,315 \\
500,496 \\
539,872 \\
526,255\end{array}$ & $\begin{array}{r}7,320 \\
3,151 \\
2,808 \\
2,525 \\
2,277 \\
3,936 \\
6,460 \\
3,848 \\
2,749 \\
1,320 \\
1,628 \\
5,964 \\
7,684 \\
6,411 \\
3,029 \\
2,513 \\
2,052 \\
1,565 \\
2,620 \\
23,126 \\
19,094 \\
2,364 \\
2,162 \\
950 \\
2,408 \\
4,278 \\
1,856 \\
536\end{array}$ & $\begin{array}{r}17 \cdot 98 \\
7 \cdot 48 \\
6 \cdot 41 \\
5 \cdot 93 \\
5 \cdot 83 \\
9 \cdot 37 \\
14 \cdot 36 \\
8 \cdot 73 \\
6 \cdot 50 \\
3 \cdot 03 \\
3 \cdot 73 \\
12 \cdot 58 \\
15 \cdot 50 \\
13 \cdot 06 \\
6 \cdot 04 \\
5 \cdot 33 \\
4 \cdot 27 \\
3 \cdot 16 \\
5 \cdot 08 \\
44 \cdot 91 \\
38 \cdot 78 \\
4 \cdot 79 \\
4 \cdot 10 \\
1 \cdot 73 \\
4 \cdot 72 \\
8 \cdot 54 \\
3 \cdot 43 \\
1 \cdot 02\end{array}$ & $\begin{array}{r}5,846 \\
4,895 \\
9,277 \\
7,354 \\
7,124 \\
5,969 \\
9,271 \\
9,548 \\
9,557 \\
9,055 \\
9,800 \\
11,349 \\
8,323 \\
8,562 \\
10,940 \\
6,588 \\
11,630 \\
10,309 \\
7,543 \\
9,293 \\
8,530 \\
7,403 \\
12,255 \\
6,173 \\
9,971 \\
9,045 \\
7,765 \\
9,185\end{array}$ & $\begin{array}{l}14 \cdot 35 \\
11 \cdot 62 \\
21 \cdot 18 \\
17 \cdot 27 \\
18 \cdot 24 \\
14 \cdot 19 \\
19 \cdot 50 \\
21 \cdot 66 \\
22 \cdot 60 \\
20 \cdot 81 \\
22 \cdot 44 \\
23 \cdot 95 \\
16 \cdot 79 \\
17 \cdot 44 \\
21 \cdot 84 \\
13 \cdot 98 \\
24 \cdot 19 \\
20 \cdot 83 \\
14 \cdot 63 \\
18 \cdot 04 \\
17 \cdot 32 \\
15 \cdot 03 \\
23 \cdot 27 \\
11 \cdot 39 \\
19.53 \\
18 \cdot 07 \\
14.38 \\
17 \cdot 46\end{array}$ \\
\hline
\end{tabular}


TABle III (APPendix).

Whooping Cough in London, from 1740 to 1831. (MARshalL.)

\begin{tabular}{|c|c|c|c|c|c|c|c|c|}
\hline Year. & $\begin{array}{l}\text { Deaths } \\
\text { by Whonping } \\
\text { Cough. }\end{array}$ & Ratio. & Year. & $\begin{array}{l}\text { Deaths } \\
\text { by Whooping } \\
\text { Cough. }\end{array}$ & Ratio. & Year. & $\begin{array}{l}\text { Deaths } \\
\text { by Whooping } \\
\text { Cough. }\end{array}$ & Ratio. \\
\hline $1740 \ldots$ & 280 & 9.09 & 1785 & 194 & 10.25 & $1830 \ldots$ & 552 & $25^{\circ} 5^{\circ}$ \\
\hline ' 41. & 100 & 3.10 & '86. & 200 & 9.77 & '31 .... & 1,738 & $68 \cdot 59$ \\
\hline ' $42 \ldots$ & 122 & $4^{\circ} 4^{8}$ & '87 & 228 & I 1.78 & & & \\
\hline ' $43 \ldots$ & 92 & 3.07 & '88 & 298 & I 5.13 & & & \\
\hline$' 44 \ldots$ & 46 & $2 \cdot 23$ & '89 & 374 & 18.02 & $1841 \ldots$ & 2,278 & 50.05 \\
\hline '45... & 135 & $6 \cdot 34$ & & & & ' $42 \ldots$. & 1,603 & 3531 \\
\hline$' 46 \ldots$ & 95 & 3.37 & 1790 . & 391 & $25^{\circ} 00$ & ' $43 \ldots$. & 1,908 & $39^{\circ} 17$ \\
\hline ' $47 \ldots$ & 151 & $5^{\circ} 92$ & '91 .... & 279 & 14.87 & $' 44 \ldots$ & 1,292 & $25^{\circ} 28$ \\
\hline ' $48 \ldots$ & 150 & 6.29 & '92 .... & 311 & I 5.38 & '45 .... & 1,816 & $37 \cdot 58$ \\
\hline \multirow[t]{2}{*}{$' 49 .}$. & 82 & $3 \cdot 21$ & '93 .... & 352 & 16.19 & ' $46 \ldots$ & 2,035 & $4 I^{\prime}$ I 5 \\
\hline & & & '94. & 469 & $24 \cdot 37$ & '47 .... & 1,600 & 27.05 \\
\hline $1750 \ldots$ & 55 & $2 \cdot 32$ & '95 .... & 311 & 1449 & '48 .... & 1,630 & $28 \cdot 21$ \\
\hline '51... & 275 & 13.08 & '96 .... & 536 & 27.79 & '49 .... & 2,349 & $34 \cdot 16$ \\
\hline 'ธ2.. & 188 & 9.17 & '97. & 367 & 2157 & & & \\
\hline '53... & 65 & 3.37 & '98 .... & 418 & $23^{\circ} 02$ & $1850 \ldots$ & 1,568 & $32^{\circ} \circ 3$ \\
\hline '54... & 336 & 14.80 & '99. & 451 & 24.87 & '51 .... & 2,185 & 3937 \\
\hline '55... & 93 & $4 \cdot 24$ & & & & '52 .... & 1,569 & 28.71 \\
\hline '56.. & 199 & 9.53 & $1800 \ldots$ & 380 & 16.47 & 'ฐ3 ... & 2,667 & 4439 \\
\hline$' 57 .$. & 239 & I I 25 & '01 .... & 428 & 22.06 & '54 .... & 2,502 & 33.95 \\
\hline '58. & 84 & 4.78 & '02. & 1,004 & $5 \mathrm{I} \cdot 8 \mathrm{I}$ & '55 .... & 2,438 & 39.36 \\
\hline \multirow[t]{2}{*}{ '59.... } & 227 & II 58 & '03 & 586 & $39^{\circ} 92$ & '56 .... & 2,092 & $36 \cdot 52$ \\
\hline & & & '04.... & 697 & $40^{\circ} 90$ & '57 .... & 2,527 & $42 \cdot 75$ \\
\hline 1760. & 414 & 22.88 & '05 .... & 703 & $40^{\circ} 05$ & '58 .... & 2,708 & $42 \cdot 25$ \\
\hline '61.. & 197 & 9.35 & '06 .... & 623 & 3472 & '59 .... & 1,742 & 28 I 6 \\
\hline '62.. & 300 & $8 \cdot 26$ & '07 .... & 439 & $23^{\circ} 94$ & & & \\
\hline '63.. & 291 & $\mathrm{II}^{\prime} \mathrm{I} 3$ & '08 .... & 326 & 16.33 & $1860 \ldots$ & 2,067 & $33^{\circ} 17$ \\
\hline '64... & 251 & 10.82 & '09 .... & 591 & $35^{\circ} 43$ & '61 .... & 3,548 & 5437 \\
\hline '65.. & 225 & $9 \cdot 68$ & & & & '62 .... & 2,168 & 32.18 \\
\hline '66.. & 213 & $9^{\circ} 99$ & $1810 \ldots$ & 449 & $22^{\circ} 57$ & '63 .... & 2,175 & 30.61 \\
\hline 67. & 364 & 16.10 & '11 ... & 486 & $28 \cdot 5 \mathrm{I}$ & '64 .... & $2,4,23$ & $3 c^{\circ} 97$ \\
\hline '68.. & 262 & I I 09 & '12 ... & 508 & $27^{\circ} 77$ & '65 .... & 2,935 & $40: 59$ \\
\hline \multirow[t]{2}{*}{ ' $69 \ldots$} & 318 & 1456 & '13 ... & 389 & 22.45 & '66 .... & 2,960 & 36.69 \\
\hline & & & '14 ... & 864 & $44^{\circ} 80$ & '67 .... & 2,278 & 32.12 \\
\hline $1770 .$. & 218 & $9 \cdot 69$ & '15 .... & 729 & $37^{\circ} 27$ & '68 .... & 2,338 & $48 \cdot 27$ \\
\hline '71.. & 249 & I I 43 & '16 ... & 666 & $32 \cdot 78$ & '69 .... & 3,769 & $25^{\circ} 19$ \\
\hline '72.. & 385 & 1477 & '17 ... & 645 & $32: 30$ & & & \\
\hline 73. & 234 & 10.80 & '18 ... & 839 & $43^{\circ} 5^{8}$ & $1870 \ldots$ & 1,956 & $25^{\circ} 13$ \\
\hline '74.. & 554 & 26.04 & '19 ... & 750 & 38.88 & '71 .... & 2,291 & 28.48 \\
\hline 75. & 224 & 10.92 & & & & '72 .... & 3,259 & $45^{\circ} 67$ \\
\hline '76.. & 187 & $9.8 \mathrm{I}$ & $1820 \ldots$ & 794 & $41^{\circ} 04$ & '73 .... & 2,620 & $34^{\circ} 72$ \\
\hline '77... & 536 & 22.97 & $' 21 \ldots$ & 614 & 33.27 & '74 .... & 1,867 & 2430 \\
\hline '78.. & 381 & 18.67 & $' 22 \ldots$ & 757 & $40^{\circ} 12$ & '75 .... & 3,204 & 39.09 \\
\hline \multirow[t]{2}{*}{ '79.... } & 268 & 13.12 & '23 ... & 799 & 38.81 & $76 \ldots$ & 2,737 & 36.52 \\
\hline & & & $24 \ldots$ & 627 & 30.99 & '77 .... & 1,817 & 23.43 \\
\hline $1780 .$. & 578 & $2 \cdot 82$ & '25 ... & 420 & 19.97 & '78 .... & 4,483 & $53 \cdot 25$ \\
\hline '81.. & 165 & 7.96 & '26 ... & 674 & 32.47 & '79 .... & 2,934 & $35^{\circ} \circ 1$ \\
\hline '82.. & 78 & 435 & '27 ... & 767 & $34^{\circ} 4^{I}$ & & & \\
\hline '83... & 268 & 1408 & '28 .... & 717 & $33^{\circ} \circ 3$ & $1880 \ldots$ & 3,516 & $42 \cdot 96$ \\
\hline '84... & 467 & 26.19 & '29 .... & 633 & 26.90 & '81.... & 1,961 & $24 \div 18$ \\
\hline
\end{tabular}


Table IV (Appendix).

\begin{tabular}{|c|c|c|c|c|}
\hline \multirow{10}{*}{ 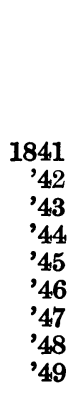 } & \multirow{4}{*}{ 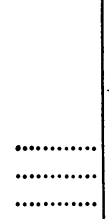 } & \multirow{3}{*}{$\begin{array}{c}\begin{array}{c}\text { Deaths by Small Pox to } \\
\text { } 100,000 \text { Deaths } \\
\text { by all Causes in London. } \\
2,311 \\
792\end{array} \\
\end{array}$} & \multicolumn{2}{|c|}{ Deaths to $10, \infty \infty$ Living. } \\
\hline & & & $\begin{array}{c}\text { Small Pox. } \\
56\end{array}$ & $\begin{array}{c}\text { Measles. } \\
52\end{array}$ \\
\hline & & & 19 & 67 \\
\hline & & 809 & 22 & 74 \\
\hline & ................ & 3,529 & 89 & $5^{8}$ \\
\hline & ................ & I, $88 \mathrm{I}$ & 44 & II 2 \\
\hline & ............... & 510 & 12 & 35 \\
\hline & ................. & 1,615 & 43 & 81 \\
\hline & ..................... & 2,804 & 72 & $5 \mathrm{I}$ \\
\hline & ..................... & 757 & 23 & 50 \\
\hline 1850 & ................. & 1,019 & 21 & 42 \\
\hline '51 & ............... & 1,913 & 45 & 55 \\
\hline '52 & ............... & $2,12 \mathrm{I}$ & 48 & 25 \\
\hline '53 & ................ & $35^{I}$ & 9 & 40 \\
\hline 54 & .............. & 941 & 28 & 56 \\
\hline '55 & .............. & 1,677 & 41 & 34 \\
\hline '56 & .............. & $9=7$ & 20 & 57 \\
\hline '57 & .............. & 263 & 6 & $5 \mathrm{I}$ \\
\hline '58 & …............ & 377 & 9 & 88 \\
\hline '59 & .................. & $\mathrm{I}, 855$ & 42 & 49 \\
\hline 1860 & ................. & $I, 44 I$ & 32 & 75 \\
\hline '61 & .............. & 332 & 8 & $3^{8}$ \\
\hline '62 & .............. & 543 & 13 & 82 \\
\hline '63 & .............. & 2,808 & 69 & 56 \\
\hline '64 & .............. & 699 & 19 & 95 \\
\hline '65 & ............. & 870 & 21 & 43 \\
\hline '66 & .............. & 1,728 & 46 & 73 \\
\hline '67 & .............. & 1,896 & 44 & 37 \\
\hline '68 & .............. & 809 & 19 & 63 \\
\hline '69 & ................ & 352 & 9 & $4^{6}$ \\
\hline 1870 & .................. & 1,253 & 30 & 45 \\
\hline 71 & .................... & 9,837 & 242 & 44 \\
\hline$' 72$ & .............. & 2,502 & 54 & 50 \\
\hline '73 & .............. & 149 & 3 & 64 \\
\hline 74 & .............. & 74 & 2 & 49 \\
\hline '75 & ............. & 56 & 1 & 40 \\
\hline $\begin{array}{l}' 76 \\
, 77\end{array}$ & ................... & 947 & 21 & 48 \\
\hline $\begin{array}{l}' 77 \\
' 78\end{array}$ & , & $\begin{array}{l}3,293 \\
1,683\end{array}$ & $\begin{array}{l}71 \\
39\end{array}$ & $\begin{array}{l}66 \\
4 I\end{array}$ \\
\hline '79 & …….................. & $\begin{array}{r}1,003 \\
536\end{array}$ & 12 & 67 \\
\hline 1880 & ............... & $5^{8} 5$ & 12 & 40 \\
\hline '81 & ……........... & 2,924 & 62 & 66 \\
\hline
\end{tabular}




\section{Discussion on Dr. Guy's Paper.}

Mr. C. WALFORD said, that some years ago he was ambitious enough to try to collect the figures relating to small pox mortality from an early period, for the whole kingdom. He, however, found it impossible to carry out his object, because the necessary records did not exist. Dr. Guy had made out a presentable and an overwhelming case with regard to London at all events. He had felt some difficulty as to what explanation would be given of the last outbreak of small pox, and although Dr. Guy's solution was somewhat startling, it appeared to be the true one. No other fact in connection with medicine was so striking as the constant and steady reduction of the deaths from small pox since the general introduction of vaccination. Mr. Griffiths Davies had authoritatively stated in the early part of the present century that the duration of human life in Great Britain had been increased by some four years during the past century and a half. He had tried to ascertain by what process of reasoning, and from what facts that strong assertion had been arrived at. The only light that he could ever throw npon it was this, that by means of vaccination there had been an obvious increase of the duration of human life. Small pox used to attack in a special degree young persons. That state of things was remedied, and he thought that at least two years' increased duration of life to the entire community might be accounted for in that way. What the other circumstances were which justified the statement about four years, he had not been able to discover. It may have been improved medical treatment. Dr. Guy had made it clear that sanitary improvements did not account for any great diminution of the deaths from small pox and epidemic diseases generally; and Dr. Parkin had broadly asserted that such improvements had actually done nothing to increase the duration of life; that mephitic vapours from time to time arose from the earth, carrying desolation and death with them. He would like to hear how any gentleman could make a presentable answer to the case so strongly put by Dr. Guy.

Mr. WhIте observed that small pox began to decline in London before any sanitary reforms were operative. He also referred to Mr. Cross's book on the great epidemic of small pox in Norwich in 1819, where it would be found that years passed over that city without any small pox, and he believed the same was true of many other parts of England. Mr. White further attached importance to the change that had taken place in the diet of the people, which had directly and indirectly affected the health of children, who are the chief victims of small pox.

Mr. BAKER drew attention to the less satisfactory character of the statistical returns prior to 1841, when compared with those subsequent to that date, quoting Dr. Farr as his authority. The speaker suggested that vaccination, by impairing the health of the children on whom it was practised, prepared them to suffer more severely by other diseases, for instance, by measles; and he thought 
that the large outlay on sanitary measures must have largely economised life. The improvements in the dwellings of the poor must have exercised a special influence for good.

Mr. BADEN-Powell said, that in the period under review, the population of London had quadrupled itself. During the same time means of communication had increased, and the people moved to and fro with much greater frequency than ever before. This seemed to bear very strongly upon the point that measles and whooping cough had increased, while small pox had decreased in recent years. The increased communication among a much greater population, gave an increased value to the results of vaccination.

Dr. KIDD said that the army was a revaccinated population, and there small pox was a disease of very rare occurrence. In 1880 there were only twenty cases of small pox and two deaths in the whole British army all the world over. He could recall no instance in which revaccination had led to serious injurious results.

Mr. Collings agreed with Mr. Baker as to the importance of sanitary measures, specifying particularly isolation and improved dwellings; and as proof of the efficacy of jsolation, quoted Dr. Hogarth. In the last century, by a system of complete isolation carried out at Chester the small pox mortality was reduced to onefifth without any vaccination whatever.

Mr. Frederick Hendriks said that the open question whether the introduction of vaccination had really increased the longevity of mankind in general during the last half century, was a very difficult one to solve in an actuarial manner, firstly, because of the evidence which tended to show that other diseases, particularly at young ages, had taken the place of small pox in destroying a large number of lives; and, secondly, because in a question of this kind it was of primary necessity to have statistics of deaths arranged according to the ages of the population, and none such existed for comparison as regards the last century or the preceding one. Mathematicians, as well as doctors, had discussed a similar question as to the improvement of longevity by the diminution of small pox before vaccination was introduced, indeed soon after the adoption of inoculation. So far back as in 1760, Daniel Bernoulli contributed a paper to the Transactions of the Paris Academy of Sciences, in which he endeavoured to show that something like three years were added to the average longevity of mankind in places where inoculation was resorted to. Bernoulli's views were immediately combated by no less a personage than Dalembert, who considered that the deduction was based on insufficient grounds. Bernoulli's conclusions were however very much strengthened by the later investigations published by Duvillard at Paris in 1806, in the form of an elaborate mathematical analysis of the influence of small pox at each age, and of the effect such a preservative as vaccination may have upon population and longevity. The subsequent researches of the English actuary, Milne, published in 1815, respecting the Carlisle mortality, gave rather a greater importance than Bernoulli and Duvillard had assigned to the extension of life consequent upon the diminution of small pox. Looking at Dr. Guy's figures presented to the Society that evening, it was certainly most 
interesting to see that the deaths from small pox, in proportion to the deaths from all causes in London, had been reduced to one-fifth of the ratio they similarly bore to deaths from all causes one hundred years ago. The results during the last century in Sweden had even been more startling than this, as the population there was in a preponderating degree a rural one. The ratio borne to deaths from all causes by the small pox deaths in Sweden had diminished to one-tenth of what they were a century ago. He (Mr. Hendriks) might perhaps be permitted to refer upon this point to his paper on the "Vital Statistics of Sweden," which was read to the Society in January, 1862. It was not, however, to be assumed as at all proved that the general longevity of Swedish lives had improved to a marked extent throughout every age. At all ages of males above 40 , there had positively been an increased mortality at the end, as compared with the commencement, of the period of one hundred years, as there tabulated with minuteness at every age. Dr. Guy had in his excellent paper contributed information in a form most useful for future study and comparison; and as the small pox question affected the lives of mankind more at infantile and younger stages than at mature and advanced ages, it was most important to have such a collection of data as Dr. Guy had so carefully brought before the Society, of the deaths in London from measles and whooping cough, the increase of which seemed to some extent to have followed with, and taken the place of, the decrease of deaths from small pox at the younger stages of life, and so as to very much complicate the satisfactory solution of the question as to how much vaccination had increased average longevity in London or elsewhere.

Professor CoRfield said it was quite impossible to account in any ordinary way for the enormous diminution in the small pox mortality during the present century, either by any change of diet, or by the slight improvement in sanitary arrangements. Any medical officer of health, if asked what disease he would compare small pox to, as regards its methods of prevention or spread, would compare it to scarlet fever or measles, and not to typhoid fever, which was a disease that could be prevented, and which would as surely be abolished as typhus had been to so great an extent by the improvements in the sanitary arrangements of houses. He agreed with previous speakers that more time was required to consider the paper and to thoroughly appreciate the figures in all their bearings, so as to be able to discuss them effectually. He very much regretted that it was not possible to have another meeting for the discussion. $\mathrm{He}$ wished to draw attention to the very remarkable facts in Table XV, which showed that between 1866 and 1876 there were years when the mortality from small pox went altogether below anything that had ever happened before. If the mortality of the epidemic of 1871 was 98 out of 100,000 , it appeared that the mortality in 1873-75 was so low as to be entirely unprecedented in the history of mankind as to which there were any statistics. $\mathrm{He}$ wished to amplify what the last speaker had said about the small pox mortality in Sweden. During the sixty-one years before the introduction of vaccination into that country, the number of years 
in which the deaths from small pox was over 10,000 was nine; while in only one year were the deaths under r,000. In that particular year they were $67 \mathrm{I}$. During the sixty-three years after the introduction of vaccination, there were forty-eight years in which the deaths were under I,000, and no year in which they reached even 3,000; while in one year their mortality was only two for the whole kingdom. Figures taken in this broad way showed the enormous change that had taken place. To account for this it was no use looking to such small things as change in diet, or even improvements in sanitary arrangements, especially while these had not been accompanied by any decrease in the mortality of similar diseases.

Mr. R. LAwson said there could be no doubt that the bills of mortality before 1837 possessed an authority far less than the statistics which Dr. Farr was so active in obtaining. Captain Graunt described them as being confined to the persons in communion with the Established Church : but upon the principle that the same relative proportion of deaths from different diseases took place among a portion of the population as among the whole, they were good for many purposes. Taking the five years before $176 b^{3}$ and the five after, the deaths from small pox in London as given in. Captain Graunt's paper, were 2 per I, ten years before and ten years after, the ratio was $2 \frac{1}{2}$ per $\mathrm{I}, 000$. Coming down to 1777, and taking five years before and five years after, the annual mortality was 3.6 per I,000. Treating the years before and after 1801 in the same way, the ratio was reduced to I.8 per 1,000. From 1841 to 1880 , notwithstanding the severe epidemic of 1871, the average mortality was only 0.35 per $\mathrm{I}, 000$. In the epidemic of 1659 , the mortality was 3.8 per I,०00; in 1661, 3.1 ; in $1772,6.24$; in $1781,5^{\circ} 47$; the mean of the last two being $5^{\circ} 9$. In the present century, the two most severe epidemics were in 1838 , when the mortality in London was $2 \cdot 2$ per 1,000 , and in 1871, when it was $2^{\circ} 4$. This latter epidemic caused a mortality in Liverpool of 3.73 per I,000; while in Amsterdam, Rotterdam, the Hague, and Utrecht, with a population of 558,000 there were 5,636 deaths, or a ratio of $\mathrm{io}$ per $\mathrm{I}, 000$. If the mortality in London had been on the same scale, there would have been $3^{2}, 270$ deaths instead of 7,912; and in Liverpool there would have been $5,87 \mathrm{I}$ deaths instead of 2, [62. As Dr. Guy had pointed out, it seemed there was something in the air which determined the virulence of small pox. The epidemic in 1871 could be traced to the Madras Presidency in 1868: it was in the northern part of India in 1869; in the Mediterranean and the South of France early in 1870; and traces of it were found in Holland, Germany, Sweden, and Scotland, before the siege of Paris, to which many persons ascribed it. As Dr. Guy very justly said, vaccination appeared to be sufficient to keep small pox in check for the time being, but every now and then a major force overpowered it to a variable extent, giving rise to epidemics; but even during these the beneficial influence of vaccination is obvious, as shown by the smaller mortality in London and Liverpool than in the Dutch towns where vaccination was much less general. 
Mr. Bounne said he had been informed by a medical friend that even when vaccination did not entirely protect, it often so far modified the influence of the disease when it was taken, that the sufferer was not even acquainted with the actual nature of the disease from which he suffered, and therefore did not take the necessary measures for isolation. The disease might thus be communicated by persons who did not know that they were capable of carrying the infection to others. With regard to sanitary improvements, they must not always expect even good measures to show an immediate result in the diminution of sufferers from the evils against which they were directed, because concurrently with them there were often other causes in existence which but for the remedial measures would have vastly increased these evils. Such was the extensive increase in the consumption of alcoholic liquors, which had tended not only to deteriorate the health of those who gave way to it, but at the same time had brought about moral reasons why such persons were not so well guarded against the dissemination of disease, and the protection of those under their care as they otherwise would have been.

Mr. William BugBY also attached importance to sanitary measures, to abstinence from alcoholic liquors, to improved medical treatment, and to the "stamping out" of disease.

Mr. GIFPEN said, that as a statistician he considered that Dr. Guy's case amounted almost to demonstration. A great many of the arguments which had been used to show that some other cause than vaccination might have possibly contributed to the great diminution of disease in the present century, were quite irrelevant to the question. For instance, with regard to the change of diet, it was altogether overlooked that Dr. Guy did not take one disease only, but also another disease of the same character. How was it then that the change of food had not operated in both cases alike. The remark applied also to improved medical treatment; there was no reason why that improvement should not have operated in the case of measles as much as in small pox, yet no such diminution was shown in the mortality from measles as in that from small pox. The same observation applied to isolation. The Society were altogether much indebted to Dr. Guy for his paper.

Dr. GuY in reply, said that the returns he had collected for the entire kingdom, showed that the ratios of deaths by small pox to deaths by all causes throughout the country, were as nearly as possible half those that obtained in London. Alluding to sanitary reforms and their effects, he said it was quite true that they had not yet made that impression upon the mortuary returns which might reasonably have been expected; but it should be borne in mind that the constant increase of our urban populations was a circumstance warring against the health of the whole people, and acting in a direction opposite to that of sanitary reforms and improvements. The more the populations of towns increased, especially where the Irish formed a considerable element, the more did sickness and mortality, as had been shown by Professor Jevons, iucrease. He did not deny that dietary changes had something to do with the health of the people, but it was quite wrong to suppose, 
as one of the speakers had done, that the end of the eighteenth century was the dividing line between a more and a less healthy diet. He gave every possible credit to what Dr. Farr had said, of the comparatively unsatisfactory character of our statistics prior to the Registration Act, but a certain importance certainly did attach to statistical returns prior to this century, for they were collected in the same way, though by less competent persons, and were governed by the same law of error or ignorance. He (Dr. Guy) had not said that small pox was not influenced by sanitary reforms, but that other diseases, such as measles, whooping cough, diarrhœa, and fever were presumably influenced to the same extent. With regard to the assertion that vaccination lowered vitality, that was scarcely a subject for discussion before that Society. It was better suited to a meeting of medical men, and there was nothing in his paper to give rise to the question; all he could say was, that he did not believe it. No doubt revaccination in grown up persons did sometimes produce very serious local consequences, but this he believed happened chiefly to persons revaccinated in an epidemic year, when both small pox and vaccination were rendered more severe by the conditions of the atmosphere which caused the epidemic. As to improved dwellings, there could be no doubt that they had saved many lives and added enormously to the comfort, and to some extent also, to the vitality of the people; but that fact did not touch the question before the meeting in any way whatever. He agreed with Mr. Baden Powell that the more dense the population the greater the mortality. Dr. Kidd had made some valuable statements with respect to revaccination in the army, and no doubt the chairman could confirm what had been said on that point. To return to sanitary reforms and improvements, it was obvious that they must have affected all the diseases given in the tables he had submitted, and yet the reduction in the case of small pox was at least ten times as great as that in any other of those diseases. Again, what had been stated with regard to isolation, applied equally to all those diseases. He received the observations made by Dr. Corfield with all the respect due to that gentleman's official position and the attention he had paid to the subject, and what he had said had strengthened the statements made in the paper. The cornparisons too, made by Mr. Lawson, all tended to confirm them. The medical man whom Mr. Bourne quoted, might be right in supposing that there were cases in which vaccination had really prevented small pox, where the patient was in a condition to communicate it to others, might go about feeling some indisposition, but being unconscious that that was due to an attack of small pox. The abuse of alcohol might also conduce to the taking small pox, and no doubt improvement in medical treatment should be taken into account. But these suggestions, and many others brought forward in the course of the discussion, Dr. Guy said scarcely grew out of the facts and figures brought forward in his paper.

The Chalrman in proposing a vote of thanks to Dr. Guy, said he quite agreed with the views expressed in the paper as to the valuable effects of vaccination as a prophylacteric, and by Dr. Kidd as to the good results of revaccination in the army. 